\title{
How affordances of chatbots cross the chasm between social and traditional enterprise systems
}

\author{
Emanuel Stoeckli ${ }^{1}$ [D $\cdot$ Christian Dremel $^{1} \cdot$ Falk Uebernickel $^{1} \cdot$ Walter Brenner $^{1}$
}

Received: 25 March 2018 / Accepted: 11 July 2019 / Published online: 8 August 2019

(C) The Author(s) 2019

\begin{abstract}
Digital and agile companies widely use chatbots in the form of integrations into enterprise messengers such as Slack and Microsoft Teams. However, there is a lack of empirical evidence about their action possibilities (i.e., affordances), for example, to link social interactions with third-party systems and processes. Therefore, we adopt a three-stage process. Grounded in a preliminary study and a qualitative study with 29 interviews from 17 organizations, we inductively derive rich contextual insights of 14 affordances and constraints, which serve as input for a Q-Methodology study that highlights five perceptional differences. We find that actualizing these affordances leads to higher-level affordances of chatbots that augment social information systems with affordances of traditional enterprise systems. Crossing the chasm between these, so far, detached systems contributes a novel perspective on how to balance novel digital with traditional systems, flexibility and malleability with stability and control, exploration with exploitation, and agility with discipline.
\end{abstract}

Keywords Social information systems $\cdot$ Enterprise systems $\cdot$ Chatbot $\cdot$ Slack $\cdot$ Enterprise messenger $\cdot$ Affordances

JEL classification $\mathrm{O} 33 \cdot \mathrm{M} 15$

\section{Introduction}

Over the last couple of years, chatbots have gained traction to improve productivity and efficiency among employees in the light of an increasing number of organizations, who adopt enterprise messengers such as Slack and Microsoft Teams (Hubbard and Bailey 2018; Riemer et al. 2018; Schatsky

This article is part of the Topical Collection on Social Information Systems Minitrack - HICCS 51

Responsible Editors: Rainer Schmidt and Selmin Nurcan

Emanuel Stoeckli

emanuel.stoeckli@unisg.ch

Christian Dremel

christian.dremel@unisg.ch

Falk Uebernickel

falk.uebernickel@unisg.ch

Walter Brenner

walter.brenner@unisg.ch

1 Institute of Information Management, University of St. Gallen, Müller-Friedberg-Strasse 8, 9000 St. Gallen, Switzerland and Gratzke 2016; Tsai 2018; vom Brocke et al. 2018). Accordingly, the worldwide chatbot market size is forecasted to increase to 1.25 billion U.S. dollars until 2025 (Grand View Research 2017). In fact, Gartner predicts that "the average person will have more conversations with bots than with their spouse" by 2020 (Levy 2016).

This rise of chatbots within enterprise messengers needs to be seen in the light of the broader wave of digitalization. Specifically, a key tenant of digitalization is distributed innovation, which is characterized by balancing flexibility and openness with stability and control (Ciriello et al. 2018a; Tilson et al. 2010; Yoo et al. 2012). Further, the growing number of application programming interfaces (APIs) enable standardized digital communication and exchange between different information systems (Eaton et al. 2015; Ghazawneh and Henfridsson 2013). In the context of instant messengers (i.e. social information systems), this has led to numerous frameworks and API's that facilitate the development and installation of chatbots in both, the enterprise context (e.g., Slack apps and integrations, HipChat bots, and Microsoft bot framework for Skype/Microsoft Teams) and the consumer context (e.g., Facebook Messenger and Telegram Bot Platform). 
The success of these enterprise messengers can be attributed, on the one hand, to their malleability and voluntariness as opposed to traditional enterprise systems which are designed to support dedicated business processes and work tasks (Koch 2008; Richter and Riemer 2013; Schmitz et al. 2016). On the other hand, a key factor for realizing organizational benefits is their integrability (Seddon et al. 2010). Taking advantage of the user-centered focus while at the same time increasing the productivity and efficiency of internal workflows are promising potentials that arise from integrating these social information systems into the enterprise landscape (Hubbard and Bailey 2018; Schatsky and Gratzke 2016).

For the sake of clarity, we now illustrate a chatbot use scenario in the context of a software developing organization (Lebeuf et al. 2018; Vehviläinen 2014). Imagine a company that integrates their software deployment workflows into their enterprise messenger. Bob, a software engineer, deploys software using an isolated command-line tool on his laptop. In contrast, imagine the same scenario, but with Bob initiating the deployment within the enterprise messenger by engaging in a textual conversation with a chatbot in a conversational group thread (accessible by other software engineers). Thus, chatbots extend the functional scope of enterprise messengers and offer new potentials. For example, by shifting from a siloed terminal into a conversational group thread, the workflow described above becomes transparent to team members.

Against this background, prior research pays little attention to two major areas. First, prior research lacks to investigate entanglements of social and traditional enterprise systems (Sedera and Lokuge 2017; Sedera et al. 2016). Yet, today's organizational IT landscape is transforming from single and monolithic enterprise systems into portfolios of information systems (Sedera et al. 2016). Given the above noted increasing possibilities to interlink different information systems and the growing relevance of distributed innovation, organizations need to explore ways to combine novel digital technologies such as social information systems with their traditional enterprise systems (Sedera and Lokuge 2017; Sedera et al. 2016). However, instead of investigating entanglements of social and traditional enterprise systems, existing information systems (IS) research largely emphasizes the contrasts between traditional enterprise systems and social information systems (Koch 2008; Mettler and Winter 2016). For instance, the latter are more user-centric than group-oriented, take in a bottom-up perspective of voluntary participation instead of top-down enforcements, enable co-evolvement of conventions and are available across projects and organizational silos rather than determining ways of working together (Koch 2008). Moreover, prior research illustrates how traditional enterprise systems enable alignment, control, interoperability, efficiency (Mettler and Winter 2016), while social information systems foster visibility, persistence, editability, and association
(Treem and Leonardi 2012). In consequence, the interrelationship and the entanglement of traditional enterprise systems and social information systems remains, until now, unclear due to their complex dynamics (Limaj et al. 2016). Accordingly, research is needed to address this lack and to elaborate on how the existing chasm of traditional information systems and social information systems can be bridged.

Second, the existing body of literature on chatbots has a strong focus on the fields of education, psychology, and linguistics and lacks in academic research on chatbots in business (Io and Lee 2017). In particular, there is little empirical research that explores the usage of chatbots within enterprises and the possibilities of chatbots to extend the functionality of the existing IT landscape even though the relevance of enterprise messengers is increasing (Lebeuf et al. 2018; Tsai 2018). Accordingly, we apply affordance theory to take into account the material properties of our technological artifacts (i.e., chatbots within enterprise messengers such as Slack and Microsoft Teams) as well as their recursive effects on social mechanisms in an organizational context (Faraj and Azad 2012; Orlikowski and Scott 2008). To date, it remains unclear which action possibilities (i.e., affordances) chatbots offer within organizations and how they provide value. Consequently, we pose the following research question:

RQ: Which affordances emerge for employees from the material properties of chatbots used within enterprises?

The goal of this research is to gain an in-depth understanding of what chatbots enable their employees to do by investigating how chatbots are actually used for everyday work in different organizational contexts. Consequently, we seek to explore novel possibilities for goal-oriented action that emerge for employees, i.e., affordances (Markus and Silver 2008).

While we take into consideration multiple enterprise messengers, Slack offers a particularly appropriate spawn and focal point for this research, because of their fast-growing ecosystem of Slack apps and integrations (Lebeuf et al. 2018; Tsai 2018). For example, they have attracted four million daily active users with a user growth of up to three and a half over the course of 2016 (The Economist 2016). Thereof, over one million users in thirty-three thousand teams operate on paid accounts (The Economist 2016) and around 90\% of these paid teams actively use chatbots in the form of Slack apps and integrations (Slack Platform Blog 2016). Moreover, due to the fact that Slack apps and integrations are actively used since 2015, work practices of employees may be more established and stable compared to the more recent rise of Microsoft Teams in 2018 driven by the free availability in combination with Office 365 (Tsai 2018).

The remainder of this article is structured as follows: First, we introduce the theory of affordances as theoretical underpinning. Then, we put the technology under investigation (i.e., 
chatbots within enterprise messengers) into the broader context of the literature on social information systems. This allows us to discuss the results in a more general theoretical context, while still acknowledging the technological materiality of chatbots and the underlying enterprise messengers. Second, the research methodology is detailed along our three research phases. Third, the results are presented along the four identified categories of affordances. Fourth, we elaborate how chatbots augment social information systems with affordances of traditional enterprise systems and we discuss our results in the light of the affordance theory, before we end with a conclusion.

\section{Theoretical background}

Information technology (IT) artifacts are "man-made cultural objects that have enduring objectified quality through its physical materiality and institutionalized practices" (Yoo 2012, p. 136). In contrast to the relatively stable structures of physical artifacts (e.g., car), the structure of digital artifacts such as enterprise messengers is pliable, extensible, re-combinable and changes dynamically over time (Faulkner and Runde 2010; Yoo 2012). In particular, chatbots are not only designed and created by humans, but at the same time, can be dynamically put into different social contexts by humans (e.g., in different project related shared conversational threads within an enterprise messenger). It is for this reason, why a sociomateriality perspective is especially valuable and acknowledges that "(1) all materiality is social in that is was created through social processes and it is interpreted and used in social contexts and (2) that all social action is possible because of some materiality" (Leonardi 2012, p. 10). Applied to the context of this research, employees may shape chatbots and, in turn, chatbots may shape employees depending on the goals and capabilities of employees (e.g., programming skills). Furthermore, sociomateriality has to be seen in the context of a global world of technological and organizational networks in which corresponding structures (both technical and social) are increasingly interdependent (Orlikowski and Barley 2001; Orlikowski and Iacono 2001). Accordingly, we aim at "simultaneously understanding the role of human agency as embedded in institutional contexts as well as the constraints and affordances of technologies as material systems" (Orlikowski and Barley 2001, p. 158). To do so, and anchored in the objective to explore what chatbots afford employees to do, we ground this research in the theory of affordances (Gibson 1977).

\section{Theory of affordances}

Having its origins in the field of ecological psychology, it is guided by the logic that animals perceive what possibilities objects in their environment offer to them (Gibson 1977). This theoretical lens suits particularly well to pursue our explorative research for two reasons. First, taking up an affordance perspective guides us to mutually investigate: (1) the causal potentials of chatbots in the form of Slack apps and integrations, and (2) the goals, motivations, characteristics and capabilities of the considered employees in their contexts. Second, the relational nature of affordances is fruitful for shedding light on the conditions under which affordance emergence, perception and actualization takes place for different user groups. In doing so, the distinction between IT artifacts and actors (e.g., users) follows the call to bring back the IT artifact and its material properties to information systems (IS) research (Benbasat and Zmud 2003; Orlikowski and Iacono 2001).

As widely adopted in IS research (Markus and Silver 2008; Pozzi et al. 2014; Savoli and Barki 2013), we conceptualize affordances as "possibilities for goal-oriented action afforded to specified user groups by technical objects" (Markus and Silver 2008, p. 622). Hence, the concept of affordances is relational as visualized in Fig. 1 and considers both (1) a user with its abilities and goals as well as (2) the material properties (e.g., features) of the IT artifact (Bernhard et al. 2013; Strong et al. 2014).

Affordances are real, that is, they exist independently of the user's perception (Gibson 1977). Figure 1 illustrates the conceptual distinction between the emergence of action potentials (i.e., the existence of an affordance for a specified user), their recognition (i.e., the perception by the user) and their realization (i.e., the actualization by the user that may lead to certain effects) (Bernhard et al. 2013; Glowalla et al. 2014; Pozzi et al. 2014). Thereby, the existing possibilities for action that an IT artefact offers to specific users are neither infinite, nor always enabling (Strong et al. 2014). In fact, the offered possibilities may also be constraining to particular users depending on their abilities and goals (Strong et al. 2014).

Affordance perception is influenced by many factors (e.g., available information) and includes the perception of nonexistent affordances (Bernhard et al. 2013). Accordingly, the material properties of an IT artifact and the respective material agency, i.e., "ways in which a technology's materiality acts" (Leonardi 2012, p. 22) and the relation to an actor trying to engage with the IT artifact may result in the perception of affordances. Perceived affordances might be actualized, depending on a user's agency, and influenced by factors such as the expected outcome or the perceived efforts to take (Bernhard et al. 2013).

Both, IT artifacts as well as actors can be considered on various levels of granularity, thus, leading to the emergence of affordances at various levels (Bygstad et al. 2016). Extant literature on affordance theory in IS research acknowledges these different levels of granularity by introducing distinct affordance concepts. Strong et al. (2014) elaborate on 
Fig. 1 Affordance concepts (Bernhard et al. 2013; Pozzi et al. 2014)

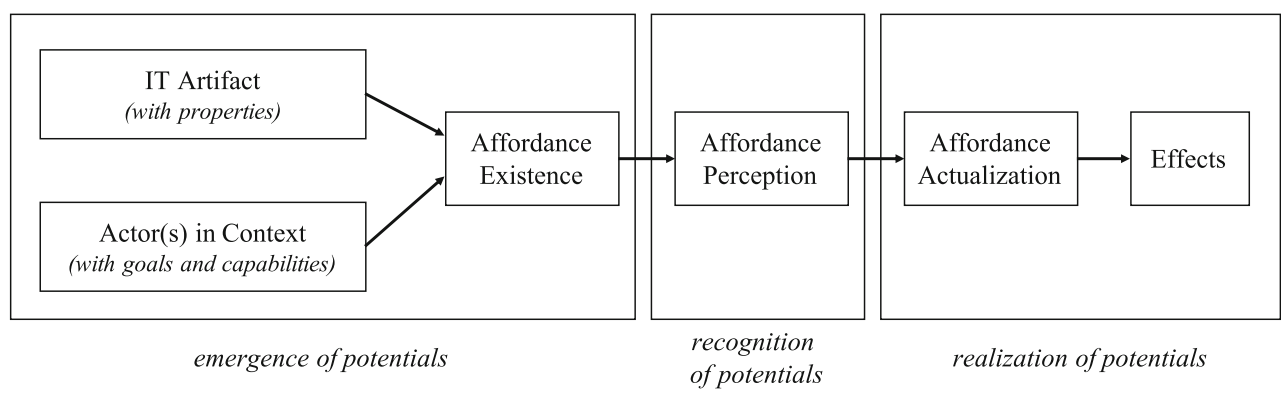

individual and organizational level affordances. At any given moment, an individual that engages with technology "is part of various organizational structures, from local work groups engaged in collective tasks, to the far-flung multi-level hierarchy that is the modern organization" (Volkoff and Strong 2017, p. 4). Accordingly, for a given user, multiple affordances may emerge from a given IT artefact. Further, the actualization of these emerging affordances is influenced by the socio-technical context in which individual users are situated (Stoeckli et al. 2019) and, from an organizational perspective, the actualization might require adaptations of the socio-technical work system (Dremel et al. 2018). Furthermore, Leonardi (2013) distinguishes between individualized, collective and shared affordances. In contrast to individualized affordances, collective affordances are "collectively created by members of a group, in the aggregate, which allows the group to do something that it could not otherwise accomplish" (Leonardi 2013, p. 752). Shared affordances are shared within a group in the way that it represents similar use of a technology (Leonardi 2013). Finally, Savoli and Barki (2013) acknowledge that IT artifacts can be seen as assemblage of individual parts, hence, leading to feature-level and system-level affordances. Among these affordances on different levels of granularity, dependencies and interactions may occur, e.g., the potential of analyzing data requires having realized the potential of collecting data (Bygstad et al. 2016; Glowalla et al. 2014; Strong et al. 2014). Such dependencies and interactions allow this research to abstract affordances from a concrete to a higher and more generalized level (Bygstad et al. 2016).

\section{Social information systems}

From a technical materiality perspective, the research at hand investigates chatbots embedded in enterprise messengers such as Slack and Microsoft Teams. However, following the theoretical lens of affordances guides to give "equal play to the material as well as the social" (Faraj and Azad 2012, p. 238). Consequently, this research has to be seen in a broader context of literature, since the considered social technologies and their surrounding organizational social structures constitute social information systems (Schlagwein and Hu 2016; Schlagwein et al. 2011). Specifically, social information systems are information systems (IS) that amplify the social capabilities of actors by creating interaction possibilities to form communities and exchange information based on open collaboration (Kaplan and Haenlein 2010; Kim et al. 2010; Schlagwein and $\mathrm{Hu}$ 2016; Schlagwein et al. 2011; Shirky 2003; von Krogh 2012).

Prior research has shown that social information systems follow the principles of egalitarianism, social production and weak ties (Schmidt and Nurcan 2009), which we now illustrate in the light of the enterprise messenger Slack.

The principle of egalitarianism is understood as providing "equal rights to all members of a society and [is] tightly connected to democratic principles" (Schmidt and Nurcan 2009, p. 202). In the context of this research, egalitarianism is manifested by allowing each user to create and join channels as well as contribute to and consume content. Within Slack, chat rooms called channels visualized as a conversational thread of messages, including textual messages, images and files (see Fig. 2). The channel can be set as open for users to join, or privately shared per invitation only. As such, the creation of channels and content is a result of social production by the users of a corresponding Slack team.

The principle of social production emphasizes that the production of information and knowledge is organized collaboratively based on free flow rather than process-driven and topdown enforced ways of working together (Benkler 2006; Schmidt and Nurcan 2009; Tapscott and Williams 2008). Due to malleability (Richter and Riemer 2013; Schmitz et al. 2016), channels can be harnessed for various purposes (e.g., to organize conversations on specific topics of interest, technologies, projects and dedicated team channels). In turn, the visibility of open channels enables the creation of weak ties.

The principle of weak ties acknowledges the characteristic of social information systems to facilitate the spontaneous creation of links (i.e., ties) between non-predetermined individuals (Granovetter 1973; Schmidt and Nurcan 2009). Furthermore, users can react to any kind of message that is posted with smileys (emojis), add answers directly in the main thread or create replies in a corresponding sub-thread. They can send direct messages to one or multiple people and can engage in video calls. Further emphasis is put on the search functionality offered across any type of message and the drag and drop of files (Slack 2017b). 


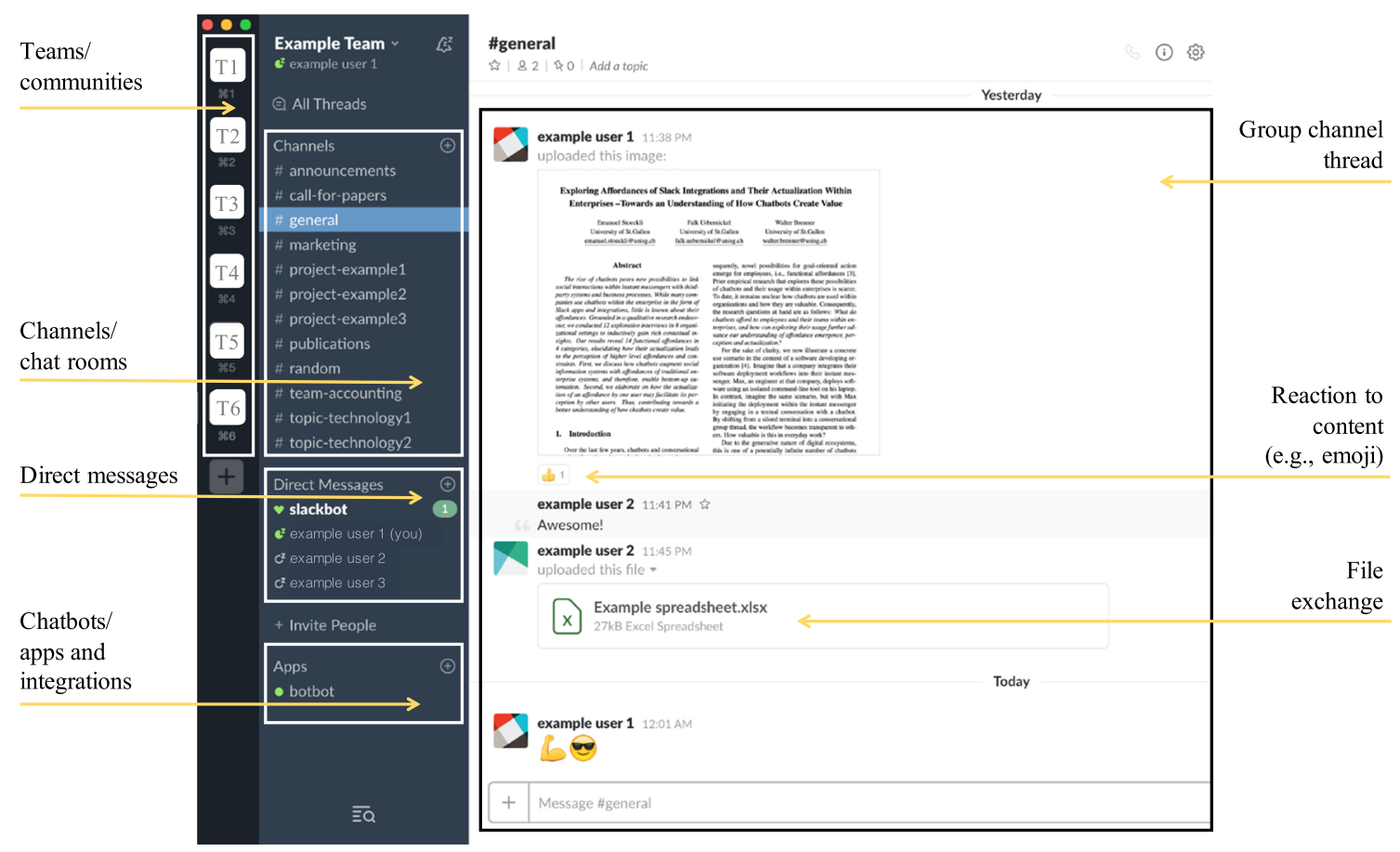

Fig. 2 Thread of a group channel within the Slack desktop app

Looking through a sociomaterial lens guided by the theory of affordance, we argue that contemporary enterprise messengers such as Slack and Microsoft Teams differ from previous forms of enterprise messengers in regard to the technical as well social structures. They offer powerful application programming interfaces (API) that allow developers to build conversational driven apps and integrations into these channels, that is, what we refer to as chatbots (see subsequent section on Chatbots). More specifically, by registering bot identities, developers can post messages into channels as chatbots. They can register commands to call third-party systems and establish bidirectional connections to send and receive messages of channels. The base functionality such as reacting with emojis is also applicable to messages posted by chatbots. In addition to textual messages, more and more visual elements are provided for chatbots, e.g., buttons (see Fig. 3) and menus with selectable options. Finally, today's enterprise messengers allow to share apps and integrations in their publicly available marketplaces, e.g., Slack's App Directory (Slack 2016a) and Microsoft's AppSource (Microsoft 2018). This has led to a growing ecosystem in terms of the number of users and the number of apps and integrations. For example, Slack's App

1:00 AM

\section{Your App APP Example text 1}

\section{Example text 2}

\section{Option A Option B Option C}

Fig. 3 Interactive buttons posted by a Slack chatbot app (Slack 2017a)
Directory listed 150 apps in December 2015 and over 385 apps in April 2016 (Slack 2016b). With this ecosystem, contemporary enterprise messengers differ from previous enterprise messengers by offering chatbots to a broader audience of users, which may add apps and integrations from the public directory to their channels (i.e., putting chatbots into their working environment).

\section{Chatbots}

At the very core, bots can be understood as automated programs which "do not require a human operator", while chatbots in particular are automated programs that interact with chat services (Gianvecchio et al. 2011, p. 1558). Consequently, the focus lies on nonhuman actors that engage in conversations with human actors, whereas an actor is "any entity that acts" (Seymour et al. 2018, p. 956). In turn, a "fully computer-based entity that exhibits, at least to some degree, autonomous behavior" is widely known as an agent (Seymour et al. 2018, p. 955).

Accordingly, several authors adopt the concept of conversational agents (Gnewuch et al. 2017; Nunamaker et al. 2011; Schuetzler et al. 2014) and investigate, for instance, the use of conversational agents in the finance industry in the form of robo-advisory (Jung et al. 2018a; Jung et al. 2017; Jung et al. 2018b). Against this backdrop, a chatbot can be seen as a type of conversational agent that is text-based (Gnewuch et al. 2017). This conceptual distinction is relevant, because conversational agents are not limited to text, but include voice-driven systems such as Apple Siri, Microsoft Cortana, Amazon 
Alexa and Google Assistant (Dale 2016). Commonly, such conversational agents provide assistance to users ranging from basic user assistance to anticipating user assistance with varying degrees of interaction and intelligence (Maedche et al. 2016). Similarly, prior research distinguishes simple agents (i.e., agents that solely act according to pre-scripted behavior) from cognitive agents with sophisticated capabilities to understand the natural language from human actors and to respond accordingly (Seymour et al. 2018).

Furthermore, agents differ in their degree of realistic visual presence. Specifically, human actors may be visually (re-)presented at varying degrees of realism through avatars, while nonhuman actors may be visually presented as visual cognitive agents, i.e., "an interactive, real-time rendered human-like entity, on a screen or in a virtual environment" (Seymour et al. 2018, p. 956). Consequently, visual cognitive agents as well as avatar-represented human actors increasingly become visually believable artificial humans with high degree of presence, thus, create realistic visual presence (Seymour et al. 2018). Similarly, social presence describes the degree to which an actor is perceived as a real and present (Short et al. 1976). Prior research even suggests that humans perceive nonhuman actors with sufficient social cues as social actors; a paradigm referred to as computers-are-social-actors (Nass and Moon 2000; Nass et al. 1995, 1994). In fact, team performance of human robot teamwork increases with a higher emotional attachment of humans to their robots (Robert 2018; You and Robert 2018). In this regard, studies also show various effects of avatars on the human perception of conversational agents. For example, facial expressions affect the perceived credibility (Cowell and Stanney 2005) and likability of avatars (Nunamaker et al. 2011). When using conversational agents for e-commerce, literature shows that avatars of sales agents not only influence satisfaction with retailers, but also the positive attitude towards products as well as greater purchase intentions (Holzwarth et al. 2006).

With the advent of automation, work is increasingly shaped by the interplay of humans and machines (Lehrer et al. 2018; vom Brocke et al. 2018). At the same time, conversational agents may not only be designed to assist humans, but with the goal to change human attitudes and behavior (Fogg 2002; Mirsch et al. 2017; Oinas-Kukkonen and Harjumaa 2009; Weinmann et al. 2016). Against this backdrop, machines increasingly take in dominant roles, which is why scholars argue that human agency may be reduced so that it becomes, in an extreme view, subordinate to automated executions: "it is humans that must react to technological stimuli rather than technology that must react to human stimuli" (Demetis and Lee 2018, p. 930). In this rather extreme perspective, humans are considered "artifacts shaped and used by the (system of) technology rather than vice versa" (Demetis and Lee 2018, p. 929). Consequently, aside from the varying degrees of (1) interaction, (2) intelligence and (3) realistic visual presence, conversational agents may differ in their dominance and persuasion, which influences (4) the degree of human agency.

To sum up, agents that engage in and assist in conversations with humans are not a novel phenomenon, per se. It is already fifty years ago, since the well-known program ELIZA replied to human input based on keyword recognition (Weizenbaum 1966). Aside from the introduced concepts, a plethora of related concepts have emerged over time, e.g., conversational interface (Knight 2016), chat agent (Crutzen et al. 2011), chatterbot (Mauldin 1994), and dialogue system (Litman and Pan 2002). However, "whether you call these things digital assistants, conversational interfaces or just chatbots, the basic concept is the same: achieve some result by conversing with a machine in a dialogic fashion, using natural language" (Dale 2016, p. 811). Nevertheless, over the years, the background of research on chatbots has changed in three major areas:

First, the technologies to build chatbots have progressed. In particular, the capabilities of information technology, precisely artificial intelligence and machine learning, have advanced. Natural language processing capabilities can now be used to extract meaning from textual input and to form reasonable responses. Thus, social interactions between humans and machines are no longer limited to chatbots operating on fixed rule-based pattern matching and simple decision trees (Schuetzler et al. 2014). Chatbots become artificially intelligent agents (Crutzen et al. 2011).

Second, the social information systems in which chatbots are embedded have changed. Originally, text-driven instant messengers provided mainly desktop computer users with virtual spaces (i.e., chat rooms or channels), e.g., based on IRC, XMPP/ Jabber, MSN and AOL (Gianvecchio et al. 2011). In the meanwhile, contemporary technologies on mobile devices are increasingly pervasive and integrated into the everyday life at home and at work (Lyytinen and Yoo 2002; Yoo 2010).

Third, the use of chatbots has evolved against the backdrop of the changing technologies to build chatbots as well as the changing technologies in which chatbots are integrated. In the 1950's, the well-known Turing test has initiated the use of chatbots in experimental settings, in which an examiner decides if a subject in a conversation is a human or a machine (Turing 1950). Accordingly, a vast body of research is concerned with passing the yet not solved imitation game (Floridi et al. 2009). Since the rising adoption of messengers in the everyday life of people, research is not limited anymore to experimental settings. In fact, WhatsApp and Facebook Messenger are the most popular mobile messaging apps worldwide with more than 1300 millions monthly active users (Statista 2018). Accordingly, research reveals chatbots in various settings, e.g., customer support (Lasek and Jessa 2013), health (Crutzen et al. 2011), education (Kerly et al. 2007) and psychology (Pilato et al. 2005). In the enterprise context, prior research on chatbots has mostly focused on cost reductions 
and computer-based support for decision making (Watson 2017).

Against this backdrop, the research at hand differs from prior research in the following two ways. First, the focus of this research is on investigating chatbots within enterprises. In contrast, academic research on chatbots primarily focuses on the fields of education, psychology, and linguistics, while there is a lack of research on chatbots in business (Io and Lee 2017). As such, we empirically investigate the use of chatbots in practice in contrast to prior research that aims at designing and evaluating chatbots (André 2008; Gnewuch et al. 2017; Kerly et al. 2007; Kim et al. 2007; Serban et al. 2017).

Second, much research strives to optimize the human-like behavior (Floridi et al. 2009; Turing 1950), e.g., increasing the perceived humanness and engagement of conversational agents through adaptive responses (Schuetzler et al. 2014) and advancing the knowledge on human-like chatbot conversations (Crutzen et al. 2011). In practice, many of today's real world examples highlight the relevance of chatbots that are far away from being intelligent and offer simple linear flows (Budiu 2018). Even though humanness of chatbots may influence its effects, emerging enterprise messengers such as Slack, Microsoft Teams, and HipChat indicate that chatbots are by no means limited to, but do include, chatbots that strive to act as human-like as possible (Slack 2016a). Consider the illustrative case from the introduction section, where a chatbot initiates the deployment workflow triggered by commands within a textual conversation. This means that the intention behind chatbots may, but do not necessarily need to lie in increasing the humanness of their conversations. In addition, it has to be acknowledged that "there are three main approaches for conversations: unilateral, bilateral, or multilateral. Unilateral conversation is used for messages, which do not require responses" (Krempels et al. 2006, p. 395).

In summary, we draw on prior research (Dale 2016; Gnewuch et al. 2017; Krempels et al. 2006; Seymour et al. 2018) to conceptualize chatbots as nonhuman actors that act as conversational agents by engaging in unilateral, bilateral or multilateral text-based conversations with human actors.

\section{Research methodology}

Our research adopts an explorative approach, because prior research on chatbots, in general, and enterprise messengers such as Slack apps and integrations, in particular, is scarce. Accordingly, a qualitative empirical research design is applied with the objective to enlighten this so far unexplored phenomenon inductively with rich contextual insights (Paré 2004; Yin 2008). Grounding our research in the interpretative paradigm allows us to gain a deeper understanding of the meaning that individuals assign to the phenomenon of interest (Klein and Myers 1999; Walsham 1995).

\section{Phase 1: Preliminary study}

Following the call to take the IT artefact as serious as its potential effects (Orlikowski and Iacono 2001), we started with a preliminary study to explore Slack and its apps and integrations in regard to its materiality. This involved examining the documentation of Slack and its API to gain an understanding of the material features. We then built a crawler, which we used to parse the Slack App Directory (Slack 2016a) on October 11, 2016. From that, we collected the names, descriptions and the associated categories (one or more from 17 categories) for each of the available apps and integrations. After an initial exploration of each category, we calculated the number of chatbots per category as well as association rules to determine how the categories relate to each other. Later in the research process, we run the crawler again before Phase 3 (Dec. 2018).

Our findings, which include the full list of publicly available Slack apps and integrations from two points in time (i.e., 2016 and 2018), allowed us to visualize the corresponding development over time (see Fig. 16). We find that a large share of available integrations is targeted at software developers. In the first run, we collected 722 Slack apps and integrations, whereas most of them were assigned to the categories of productivity $(n=223)$, social and fun $(n=188)$, communication $(n=157)$, developer tools $(n=146)$ and bots $(n=130)$.

Overall, the preliminary study adds to the research at hand in two ways. First, we obtained an understanding of the potential user groups relevant for the recruitment of interviewees and participants of the Q-Methodology study as well as it served as initial overview of potential use scenarios of apps and integrations within Slack. Second, the preliminary study helps in the interpretation of our results and enriches the discussion.

\section{Phase 2: Qualitative study}

\section{Data collection}

We conducted 29 semi-structured interviews with employees from 17 companies to investigate their usage of chatbots within their work context (see Table 1). The interviews were conducted in two phases from May 2016 to January 2017 and from October 2018 to November 2018 (see Phase 2a and 2b in Fig. 4).

The interviewee selection process was as follows. The overarching goal was to collect empirical data from multiple social and organizational contexts, because our objective is to explore a broad range of affordances, 
Table 1 List of interviews (\#1 to \#29) with details on interview partners and the context of chatbot usage

\begin{tabular}{|c|c|c|c|c|}
\hline Id & Job position of interviewee & $\begin{array}{l}\text { Programming } \\
\text { skills }\end{array}$ & Organizational context & Assimilation (Messenger) \\
\hline$\# 1, \# 2$ & Lead Software Engineer & Yes & \multirow{2}{*}{$\begin{array}{l}\text { Alpha (Internet of Things software provider } \\
\text { for facility management, 10-50 employees, } \\
\text { Switzerland) }\end{array}$} & \multirow[t]{2}{*}{ Routinisation (Slack) } \\
\hline$\# 3$ & Chief Executive Officer & No & & \\
\hline \#4 & R\&D Team Lead, Vice President & Yes & \multirow{2}{*}{$\begin{array}{l}\text { Beta (Innovation team of a financial service } \\
\text { provider, 1000-5000 employees, United } \\
\text { States) }\end{array}$} & \multirow[t]{2}{*}{ Infusion (Slack) } \\
\hline \#5 & Innovation Architect & Yes & & \\
\hline \#6 & Senior Consultant & No & \multirow{4}{*}{$\begin{array}{l}\text { Gamma (Innovation consultancy, } 10-50 \\
\text { employees, Germany and Switzerland) }\end{array}$} & \multirow[t]{4}{*}{ Acceptance (Slack) } \\
\hline \#7, \#8 & Senior Consultant & No & & \\
\hline \#9 & Consulting Manager & No & & \\
\hline$\# 10$ & Senior Consultant & No & & \\
\hline \#11 & $\begin{array}{l}\text { Head of Development and } \\
\text { Interaction Design }\end{array}$ & Yes & \multirow[t]{2}{*}{$\begin{array}{l}\text { Delta (Technical consultancy and software } \\
\text { company, 50-100 employees, Switzerland) }\end{array}$} & \multirow[t]{2}{*}{ Routinisation (Slack) } \\
\hline \#12 & Deputy Chief Technology Officer & Yes & & \\
\hline$\# 13$ & Product Manager & No & $\begin{array}{l}\text { Epsilon (Telecommunication, } 50-100 \mathrm{em}- \\
\text { ployees within the Slack team/10 k-100 k } \\
\text { in total, Switzerland) }\end{array}$ & Routinisation (Slack) \\
\hline$\# 14$ & Chief Executive Officer & No & $\begin{array}{l}\text { Zeta (Human resources \& recruiting, 5-10 } \\
\text { employees, Germany) }\end{array}$ & Acceptance (Slack) \\
\hline \#15 & Head of Software and Infrastructure & Yes & $\begin{array}{l}\text { Eta (Software company, 10-50 employees, } \\
\text { Switzerland) }\end{array}$ & Infusion (Slack) \\
\hline \#16 & Innovation Manager & No & $\begin{array}{l}\text { Theta (Energy sector, 100-200 employees, } \\
\text { Switzerland) }\end{array}$ & Routinisation (Slack) \\
\hline \#17 & Product Owner & Yes & \multirow{4}{*}{$\begin{array}{l}\text { Iota (FinTech company in the real estate } \\
\text { sector, strong growth from }<50 \text { to } 100-200 \\
\text { employees within one year, Switzerland) }\end{array}$} & \multirow[t]{4}{*}{ Routinisation (Slack) } \\
\hline \#18 & Squad Lead & No & & \\
\hline \#19 & Front-End Developer & Yes & & \\
\hline$\# 20$ & Agile Coach & No & & \\
\hline \#21 & Senior Software Engineer & Yes & $\begin{array}{l}\text { Kappa (Cyber security service provider, } \\
100-200 \text { employees, Switzerland) }\end{array}$ & $\begin{array}{l}\text { Routinisation (Slack, extended } \\
\text { team use) }\end{array}$ \\
\hline \#22 & $\begin{array}{l}\text { Software Engineer \& Technical } \\
\text { Program Manager }\end{array}$ & Yes & $\begin{array}{l}\text { Lambda (Software provider for travel } \\
\text { agencies, } 10-50 \text { employees, Switzerland) }\end{array}$ & $\begin{array}{l}\text { Infusion (Slack, extended team } \\
\text { use) }\end{array}$ \\
\hline \#23 & Founder and Software Developer & Yes & $\begin{array}{l}\text { Mu (Software development company, 10-50 } \\
\text { employees, Switzerland) }\end{array}$ & $\begin{array}{l}\text { Routinisation (Slack, } \\
\text { inter-organizational use) }\end{array}$ \\
\hline \#24 & Manager in Finance and Operations & No & $\begin{array}{l}\mathrm{Nu} \text { (Software provider in the cryptocurrency } \\
\text { industry, } 50-100 \text { employees, Switzerland) }\end{array}$ & $\begin{array}{l}\text { Routinisation (Slack, distributed/ } \\
\text { virtual team use) }\end{array}$ \\
\hline \#25 & Chief Executive Officer & No & $\begin{array}{l}\text { Xi (Game development company, 50-100 } \\
\text { employees, Germany) }\end{array}$ & Routinisation (Telegram) \\
\hline \#26 & Testmanager / IT Teamlead & Yes & \multirow{2}{*}{$\begin{array}{l}\text { Omicron (Manufacturing, } 10 \mathrm{k}-100 \mathrm{k} \\
\text { employees, global presence with head- } \\
\text { quarter in Switzerland) }\end{array}$} & \multirow[t]{2}{*}{ Acceptance (Microsoft Teams) } \\
\hline \#27 & Head of Software Development & Yes & & \\
\hline \#28 & Senior Consultant & No & $\begin{array}{l}\mathrm{Pi} \text { (IT service management, } 1000-5000 \\
\text { employees, } 100-200 \text { in Germany) }\end{array}$ & Adoption (Microsoft Teams) \\
\hline \#29 & Chief Executive Officer & No & $\begin{array}{l}\text { Rho (Technology service provider, } 10-50 \\
\text { employees, Switzerland). }\end{array}$ & Routinisation (Microsoft Teams) \\
\hline
\end{tabular}

which are, per se, contextual. Consequently, we selected interviewees form different organizational contexts so that a variety of industries and company sizes is included. All interviewees were recruited using Snowball sampling to obtain a sufficient set of interviewees (Myers and Newman 2007). In doing so, we only included interviewees that have used the corresponding enterprise messenger (i.e., Slack, Microsoft Teams or Telegram) as well as the corresponding chatbots (e.g., Slack apps and integrations).
In Phase 2a, we searched for employees in organizations that use Slack together with Slack apps and integrations. Thereby, the interviewee selection process was based on the findings from the preliminary study. Specifically, crawling the Slack App Directory showed that a large share of available integrations is targeted at software developers (e.g., 146 apps and integrations are assigned to the category developer tools). To prevent an overemphasis on affordances for software developers, we selected about the same number of interviewees with and without programming skills (see Table 1). 


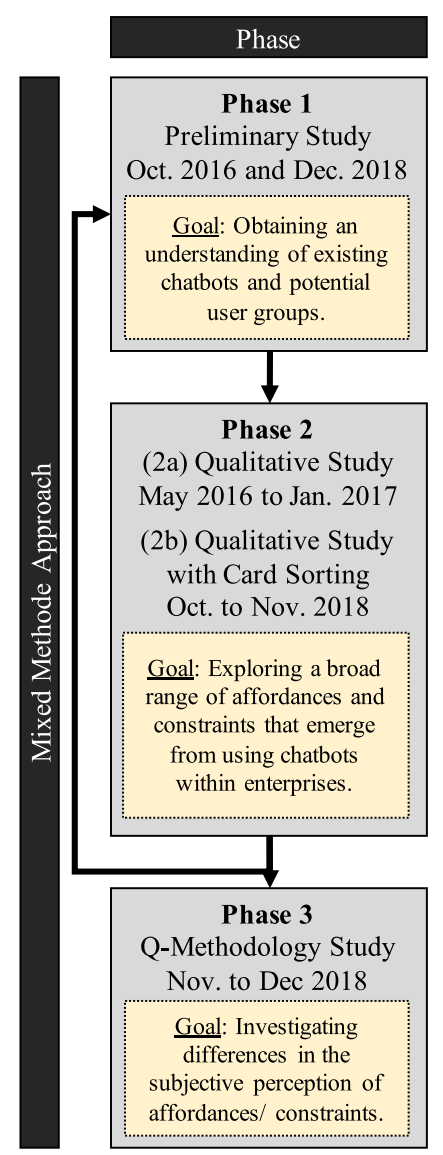

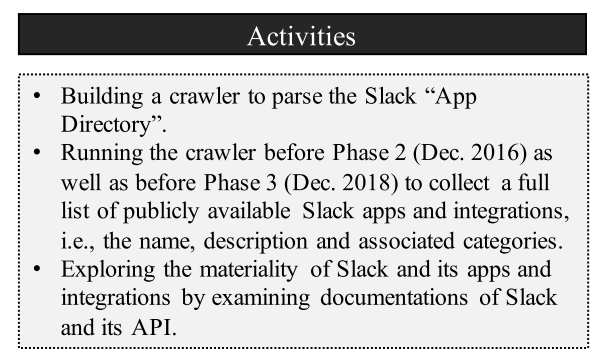

- Conducting 12 explorative semi-structured interviews in 8 organizational settings to inductively gain rich contextual insights and additional sources of evidence (e.g., screenshots).

- Qualitative data analysis consisting of open, axial, and selective coding (Corbin \& Strauss, 1990).

- Conducting 17 additional interviews based on theoretical sampling following three purposes: 1) Evolvement over time (4 interviews within companies from Phase $2 \mathrm{a}$ and 4 interviews within a company that experienced fast growth)

2) Distributed and virtual settings (4 interviews)

3) Differences in messengers (5 interviews)

In total, 29 interviews were conducted.

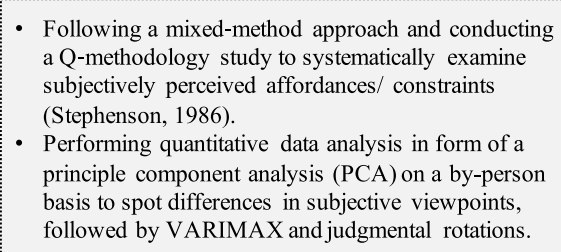

Following a mixed-method approach and conducting a Q-methodology study to systematically examine subjectively perceived affordances/ constraints

(Stephenson, 1986).

principle componen followed by VARIMAX and judgmental rotations.

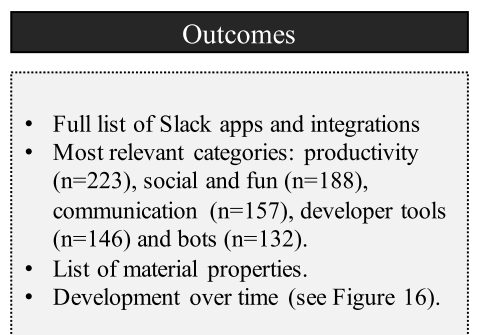

- 14 affordances and constraints, elucidating how their actualization leads to the perception of higher level affordances.

- Elaboration on how chatbots augment social information systems with affordances of traditional enterprise systems, i.e., alignment, control, interoperability, and efficiency.

- Elaboration on how the actualization of an affordance by one user may facilitate perceptions of higher-level affordances and constraints by other users.

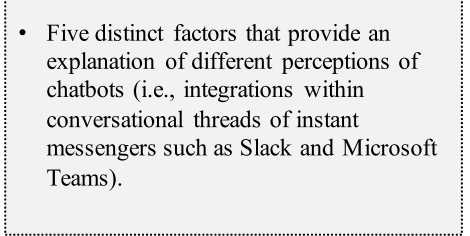

Fig. 4 Research approach with three phases at a glance

In Phase $2 b$, the interviewee selection process followed a theoretical sampling approach that is grounded in three purposes. First, roughly two years after conducting the first interviews we aimed at exploring how the usage of chatbots within enterprise messengers evolved over time. This is why we conducted 4 additional interviews with interviewees from companies that participated already in Phase 2a (see Alpha and Gamma in Table 1) as well as 4 interviews with employees working in a fast-growing company (see Iota in Table 1). More specifically, we selected Alpha and Gamma, since both organizations experienced changes such as growth and office relocation. In both companies (i.e., Alpha and Gamma), we interviewed at least one interviewee twice to compare the perceptional changes of the same person over time. Second, we aimed at exploring distributed, virtual and extended team settings, which is why we conducted 4 additional interviews (i.e., Interview \#21 to \#24). Third, we strived to understand differences in tooling. To do so, we conducted 5 additional interviews with employees of organizations that rely on Microsoft Teams and Telegram (i.e., Interview \#25 to \#29). In total, we conducted 17 additional interviews in Phase $2 \mathrm{~b}$ (leading to an overall number of 29 interviews).

The interview process was as follows. The interviews lasted between 30 and $100 \mathrm{~min}$ (with an average of $48 \mathrm{~min}$ ) and were recorded as well as transcribed right after conduction. To prevent misunderstandings and to increase the expressiveness of the statements, we either conducted the interviews in German or English depending on the native tongue of the interviewee. Grounded in open-ended questions, the interviewees were initially asked to describe how their enterprise messenger and chatbots are embedded in their everyday work. Accordingly, we characterize the studied enterprises in Table 1 in regard to the assimilation of their enterprise messenger in terms of adoption (i.e., decision to use), acceptance (i.e., committed to use), routinisation (i.e., frequent use), and infusion (i.e., comprehensive and sophisticated use) (Wang et al. 2012).

Due to the semi-structured nature, we were able to dig deeper when the interviewees mentioned interesting and unexpected ways to harness chatbots for their routines (Paré 2004). In the beginning, we asked general questions to get to know the interviewees, e.g., their job position and tasks. Then, we asked what role the corresponding enterprise messenger in general plays in their daily work, e.g., by probing work practices and typical workday journeys. Questions relating to chatbots ranged from today's perceived action possibilities, benefits as well as disadvantages and constraints. Finally, we moved from questions that referred to today's use towards 
questions that addressed changes in usage over time as well as planned and expected future use potentials of chatbots to accomplish individual and organizational goals. From about a quarter of the organizations, at least one interviewee additionally showed us on a tablet or computer how their team uses chatbots.

In Phase $2 \mathrm{~b}$, we additionally employed card sorting of the emergent list of identified affordances (Fincher and Tenenberg 2005). Specifically, each identified affordance (i.e., 14 affordances across 4 categories) was printed on card and together with two concrete examples from Phase 2a. Category by category the interviewees had to comment on their perceptions of each affordance, while sorting the cards by perceived relevance for their organizational context. Finally, the interviewees sorted the four categories of affordances by relevance.

\section{Qualitative data analysis}

To proceed in a rigorous way, we have collected and analyzed data iteratively until a coherent picture emerged (Corbin and Strauss 1990; Klein and Myers 1999). During the data analysis we performed an interwoven three-step approach for our qualitative data analysis consisting of open, axial and selective coding resulting in a total of 1613 codes (Corbin and Strauss 1990). In the open coding procedure, we inductively coded concepts to condense the transcripts and obtain an overview (Yin 2008). During the axial coding procedure, the coding structure was based on our theoretical underpinning: properties of the IT artifacts, properties of the actors (related to their goals, capabilities and contexts), and perceived and actualized affordances as well as constraints. In this process, the identified axial codes were grouped in categories (e.g., Category 1 to Category 4 presented in the results section). Through iteratively making connections between the fractured codes, a core theme emerged (Strauss and Corbin 1990). That is, different higher-level affordances and constraints emerge for members of a group channel as a consequence of the actualization of a lower-level affordance in this channel by a (potentially other) user. Consequently, we sharpened the relations between the identified affordances and constraints in the selective coding procedure. Following the principle of theoretical sensitivity (Corbin and Strauss 1990; Strauss and Corbin 1990), we built on Bygstad et al. (2016) to analyze how the actualization of lower-level affordances and constraints results in higher-level mechanisms. Specifically, our coding structure was extended with higher-level affordances, while continuing to strengthen the codes relating to relevant properties of IT artifacts and actors.

During the entire coding procedure, we triangulated multiple sources of evidence with the software MAXQDA 12 (Yin 2008). This included the transcribed interview recordings, notes and observations, with supplementary data provided by the companies: (1) screenshots of chatbots in use, (2) lists of chatbots in use, (3) documentations, (4) blog articles referred by one of the interviewees (which is also the author of the blog article), and (5) a video recording of a practiceoriented conference presentation (team of Company Beta) on how they harness chatbots for software development and operations. This allowed us to examine chatbots in use from different sides and in different embedded contexts (Klein and Myers 1999; Orlikowski and Iacono 2001).

Sensitivity, that is, the authors ability "to identify what data is significant and to assign it a meaning" (Halaweh 2012, p. 36) is crucial for interpretative research that relies on human interpretations and meanings (Walsham 1995). Sensitivity can come "from experience, especially if the researcher is familiar with the subject under investigation" (Halaweh 2012, p. 36). From this point of view, it was an advantage that the first and third author of this article use Slack apps and integrations in their daily lives, because it helped them to understand the statements made by the study participants. On the other hand, to minimize salience bias as well as to maintain a critical distance between the personal use of Slack apps and integrations of the researchers and the views of interviewees, we cross-checked the transcriptions with the second author (not an active user of enterprise messengers) and generated a shared meaning through multiple interactions in which we engaged back and forth with the empirical data, theory and our emergent coding schema (Walsham 1995, 2006).

\section{Phase 3: Q-methodology study}

To further explore in more detail the mental models that employees have developed when using chatbots (i.e., integrations into conversational threads), we have chosen to apply a mixed-method approach called Q-methodology, as it offers a rigorous and systematic way for capturing human subjectivity (Mettler and Wulf 2018; Stephenson 1935, 1986).

Though Q-methodology is particularly used in other research fields as IS research, for instance health services research (Baker et al. 2014; Stenner et al. 2003), a small number of articles have proven its usefulness for IS research. Specifically, adopting a Q-methodology in IS research has proven to be valuable to investigate differences in the decision-making of project managers (Tractinsky and Jarvenpaa 1995), to segment the ecommerce industry based on the subjective assessment of e-commerce providers (Storey et al. 2000), and to explore user resistance in enterprise implementation (Klaus et al. 2010). In particular, when exploring affordances which technological artifacts provide, it proved a useful tool to systematically analyze the subjective perception of these artifacts (cf. Mettler et al. 2017; Mettler and Wulf 2018). Both of the latter studies draw on the affordance theory to study the attitudes towards adopting service robots (Mettler et al. 2017) and to explore the mental models of employees 
who are faced with the introduction of physiolytics (Mettler and Wulf 2018).

Q-methodology is deemed as suitable for in-depth study of situations where the subjective perception of a study's participants is of special interest - in our cases the perception and actualization of affordances (McKeown and Thomas 2013; Tractinsky and Jarvenpaa 1995). Thus, Q-methodology attaches particular importance to the sampling of subjective statements. Yet, it allows to construe generalization while at the same time maintaining a high level of phenomenology as well as acknowledging and considering the subjectivity of respondents (Dziopa and Ahern 2011; Wingreen et al. 2009). As such, Q-methodology can be seen at the interception of quantitative and qualitative research (Klaus et al. 2010). Finally, Q-methodology often uncovers unusual or counterintuitive patterns which are not related to a study participant's characteristics and may thus be neglected by typical survey-based studies (Zabala and Pascual 2016).

Figure 5 highlights four main parts of Q-methodology studies (Brown 1993; Van Exel and De Graaf 2005): (1) collecting a wide range of perspectives on a topic and selecting a set of statements referred to as the Q-sample or Q-set, (2) purposefully selecting a set of participants referred to as the P-set, (3) asking the participants to conduct a comparison and ranking of the statements referred to as the Q-sort, and, finally, (4) analyzing and interpreting the results by performing statistical factor analysis. We will now describe how we conducted these steps.

\section{Q-set development procedure}

The foundation of each Q-Methodology study lies in collecting subjective statements (i.e., opinions, tastes, preferences, sentiments, motives, but not facts) that represent the perceptions of a certain topic of interest, which is referred to as the concourse (Brown 1993). According Q-Methodology, these statements can come from various sources (e.g., derived from interviews, participant observations, literature, media reports, or created from scratch) and can be presented in various formats (e.g., text, pictures, paintings, music, videos) (Brown 1993; Donner 2001; Van Exel and De Graaf 2005). Then, a subset of the statements is drawn from the concourse to develop the Q-Set.

In our research, we ground the development of the Q-Set in the rich qualitative insights gathered in Phase 2 of this research that comprises interviews $24 \mathrm{~h}$ of interviews with users of chatbots within enterprise messengers (e.g., apps and integrations within Slack) across 17 organizations (see previous section). From that, a set of 28 statements was derived that covers employees' views on affordances (14 statements) and constraints (14 statements). By considering both affordances as well as constraints, our Q-Set covers a heterogeneous set of statements that broadly represent perceptions that proved to be relevant (Watts and Stenner 2005). Furthermore, we relied on guidelines to ensure that the formulation of the statements is similar in style (Donner 2001). Specifically, we choose a framing of the statements so that each makes an assertion about an

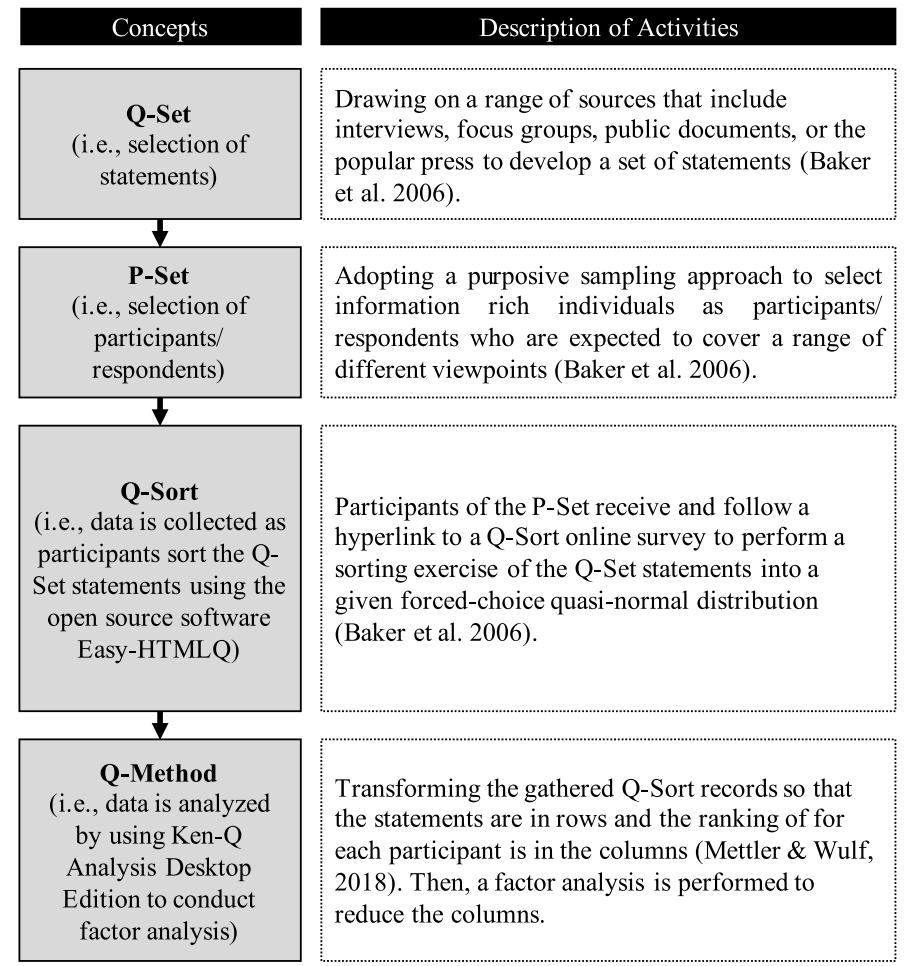

Fig. 5 Overview of Q-methodology concepts and procedure of this study
Application of Activities to this Research Context

A Q-Set of 28 statements is developed based on the identified affordances and constraints from Phase 2 (i.e., the statements are based on rich qualitative data from 29 interviews).

A P-Set of 28 participants were purposeful selected based on the insights from Phase 2 so that employees that use Slack as their main tool as well as complementary to Email were covered.

A five step process is followed:

(1) introduction of background and process,

(2) individual sort of cards into agree, neutral, and disagree,

(3) review and detailed sort into forced-choice distribution from agree $(+2)$ to disagree $(-2)$,

(4) commenting on extreme values ( +2 and -2$)$, and

(5) descriptive question survey.

Five distinct factors with eigenvalues greater than 1.00 are extracted by performing a principle component analysis (PCA) on a by-person basis. Overall, these factors cumulatively explain $67 \%$ of the variance. 
action/ value potential or constraint/ limitation of chatbots/ integrations within enterprise messengers (Watts and Stenner 2005). For example, the statement that corresponds to affordance AFF-01 was formulated as follows: "I perceive integrations into Slack, HipChat or similar as valuable for receiving status notifications and updates from third-party systems within channels". On the other hand, constraint CON04 was formulated as follows: "I perceive Slack, HipChat or similar messenger integrations as constraining, since they lead to information overload".

\section{P-set recruitment procedure}

Q-Methodology studies are conducted with a relatively small number of participants (Stephenson 1935; Van Exel and De Graaf 2005) that is usually smaller than the Q-set of statements (Brouwer 1999) and that enables the comparison of the resulting factors with each another (Brown 1980). Following this methodological backdrop, and similar to Phase 2, a purposeful sample of 28 information-rich participants was recruited to take part in the Q-sort survey. Note that the key consequence of non-random sampling is that inferences are only made about the viewpoints of the participating groups on the given subject (i.e., the factors that influence the perception of chatbots within enterprise messengers), but not about the wider population and the distribution of the viewpoints among the respondents (Baker et al. 2006; Davies and Hodge 2007; Watts and Stenner 2012).

Next, we selected employees who are expected to have a clear and distinct view on chatbots within enterprises messengers. Namely, we focused on knowledge workers that perform mainly digital work, that is, "[an] effort to create digital goods or that makes substantial use of digital tools "(Durward et al. 2016, p.283) and that use chatbots within enterprise messengers as part of their daily work. Accordingly, the descriptive statistics of our list of respondents shows that $96 \%$ of the participating knowledge workers engage in work with digital input and output, while $4 \%$ of them engage in physical work (i.e., consultants that conduct face-to-face workshops). $75 \%$ of the respondents use their enterprise messenger for work in a dispersed, distributed, or extended team setting, whereas $25 \%$ use it locally. Furthermore, $39 \%$ of the participants work in micro enterprises (fewer than 10 employees), $36 \%$ in small enterprises (10 to 49 employees), $18 \%$ in medium-sized enterprise (50 to 249 employees), and $7 \%$ in large enterprise (250 or more employees). Within these work contexts, $57 \%$ of the study participants use their enterprise messenger as their main collaboration tool at work (i.e., replaces internal email), while $43 \%$ use it as a complementary tool. Moreover, most of them were somewhat familiar with programming integrations (71\%). Lastly, $21 \%$ were females and $79 \%$ males.

\section{Q-sort study procedure}

All participants received links to a Q-Sort survey tool (see Fig. 6), which was setup using a fork ${ }^{1}$ of the open source software Easy-HtmlQ ${ }^{2}$ that allows working with the database system Firebase.

Aside from configurational changes (e.g., introduction text, guidance through the individual steps, statements), we additionally adjusted the source code of the tool so that color priming is minimized (i.e., we removed the red and green color to ensure that participants are not primed to agree on the provided statements) and usability is increased (i.e., we implemented a hover feature for statements that were already sorted).

Each participant was guided through five steps. Step 1 introduced the background, the goal and the expected duration of the study as well as author-related contact information. In Step 2 each statement was shown individually to the participants (in random order), which then had to select "agree", "neutral" or "disagree" by either using drag and drop or by pressing the corresponding keyboard shortcuts. Following the widely established procedure of using forced-choice quasinormal distributions in Q-methodology studies (McKeown and Thomas 2013), Step 3 comprised sorting the statements into the five levels of agreement ranging from +2 (agree) to -2 (disagree). The instructions guided the participants to start with the agree pile, read the statements again, select the four statements that participants mostly agree with and place them on the right side of the score sheet below the +2 (see Fig. 6). This process was continued with sorting statements into the piles for statements that are perceived as most disagreed $(-2)$, partly agreed $(+1)$, disagreed $(-1)$ as well as neutral (0). Step 4 involved commenting on the four most agreed and disagreed statements. Finally, in Step 5, the participants were asked to answer a set of descriptive questions (e.g., age, sex, job role, industry, company size) as well as indicate the relevance of chatbots for different types of channels on a scale from 1 to 5 (e.g., project team channels, inter-organizational channels).

\section{Quantitative data analysis}

We used the software Ken-Q Analysis Desktop Edition (KADE) (Banasick 2019) which offers dedicated calculation functionalities for the analysis of Q-Methodology studies (Version 1.0.0). We started by exporting all Q-Sort survey records from the Firebase database and calculated the correlations between the respondents, which resulted in a by-person correlation matrix (Watts and Stenner 2005). At the core of QMethodology, the correlation matrix lies the foundation to apply factor analysis to determine a set of basically different

\footnotetext{
${ }_{1}^{1}$ https://github.com/shawnbanasick/easy-htmlq

2 https://github.com/aproxima/htmlq
} 


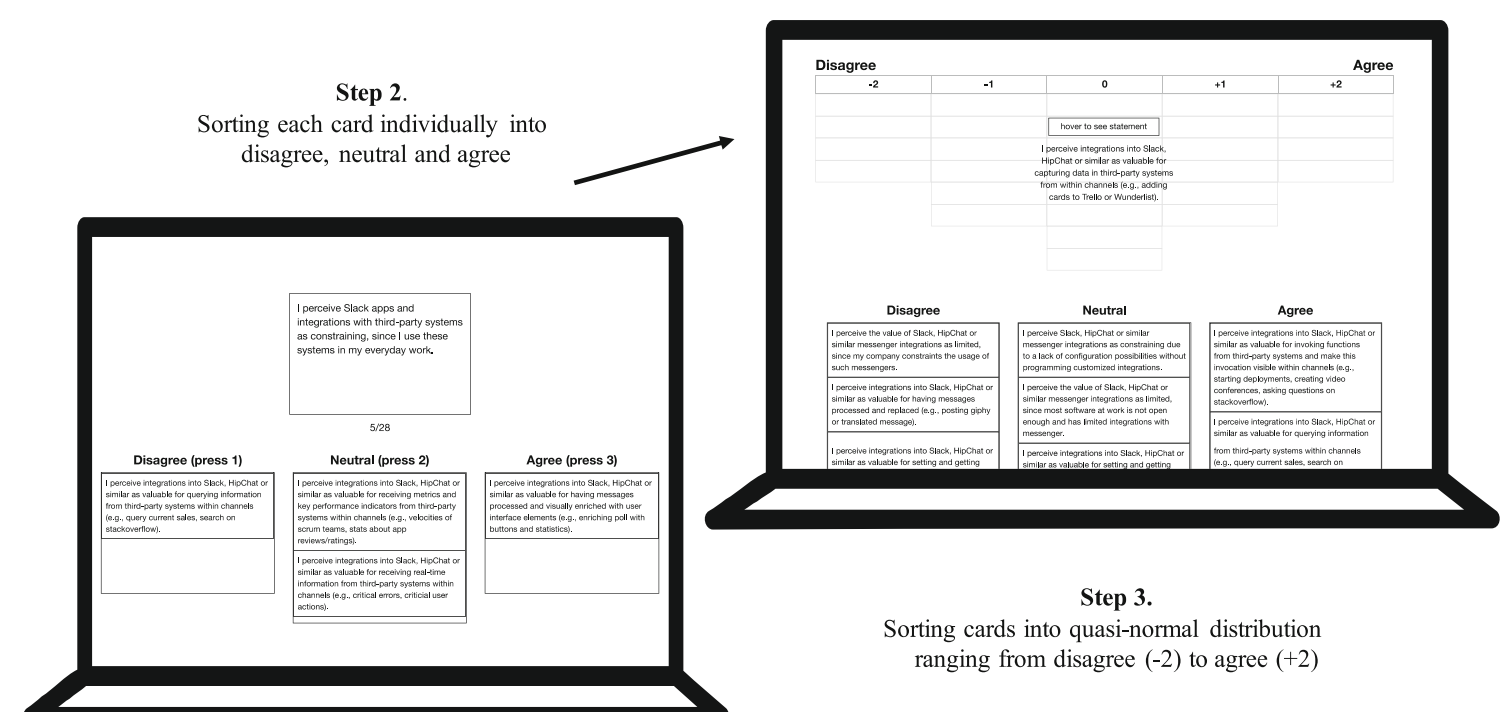

Fig. 6 Q-sort survey tool used to conduct the Q-methodology study

Q-sorts that are evident in the data (Brown 1993). Note that the way factor analysis is applied is on a by-Q sort (i.e., byperson) level, which means that each record is transposed so that the statements are in rows and the sort values (i.e., from -2 to +2 ) are in columns (i.e., one column for each participant) (Mettler and Wulf 2018).

To perform the factor analysis, we used principle components analysis (PCA) with Varimax rotation of seven factors to maximize statistical differences (McKeown and Thomas 2013). To do so, on the one hand, we calculated eigenvalues, the explained variance (in percent) as well as the cumulative explained variance (in percent) for each factor so that we were able to extract seven factors with eigenvalues greater than 1.00. This is a widely applied criteria for initially selecting factors (Coogan and Herrington 2011; Donner 2001), however, scholars commonly agree to critically reflect the number of factors to include in the final selection (McKeown and Thomas 2013).

Therefore, we proceeded with calculating the idealized Qsorts for each factor and read carefully through the corresponding statements. Basic statistics on normal distributions suggests to perform calculations with a standard error of 2.58 for the 99.5 percentile point. To decide on the Q-Sorts to include for each factor, we calculated the value for significant factors loadings as follows: $2.58 * 1 / \sqrt{ }$ (number of statements $)=2.58 * 0.189=0.488$. Accordingly, a Q-sort was included if greater than 0.488 for a given factor. For each factor we calculated the distinguishing statements with $p<0.05$ and $p<0.01$ and checked for which statement the $\mathrm{z}$-Score is higher or lower compared to all of the other factors. With this foundation, we applied theoretical or so-called judgmental rotation, which is recommended to harness domain knowledge to consider the factors from different angles before choosing a factor solution (e.g., Baker et al. 2006; Brown 1980, 1993).
Finally, we extracted five factors with eigenvalues greater than 1.00 and a cumulative explanation of $67 \%$ of the variance. With this decision we are in line with the eigenvalue criteria (Coogan and Herrington 2011; Donner 2001) and we ensure that at least two Q-sorts loadings are significant per factor (Watts and Stenner 2012). As such, these five factors represent five distinct interpretations of the relationship between employees and chatbots, since each factor can be understood as a viewpoint that is commonly shared between groups of similarly minded employees (i.e., they have similarly sorted the affordances and constraints statements into the forced-choice quasi-normal distribution). Going carefully through the idealized Q-sorts and comparing the distinguishing statements with the respondents (given their descriptive statistics and comments) allowed us to assign appropriate names to the factors.

\section{Results}

Our research reveals 14 lower-level affordances and 14 constraints of chatbots within enterprises. In the following these affordances and constraints are illustrated along four categories by providing empirical evidence from exemplary actualization contexts (see Tables 2, 3, 4, and 5). We find that the actualization of these lower-level affordances as well as constraints in group channels offer higher-level affordances that emerge for the members of this channel (see Fig. 7). It is in the very nature of affordance theory that technologies provide different possibilities to different people. Accordingly, the second part of the results section reveals how employees weigh the identified affordances and constraints against each other by pointing out similarities and differences in perception along five factors identified in the Q-Methodology study. 
Central theme:

Emergence of higher-level affordances as a consequence of the actualization of lower-level affordances and constraints

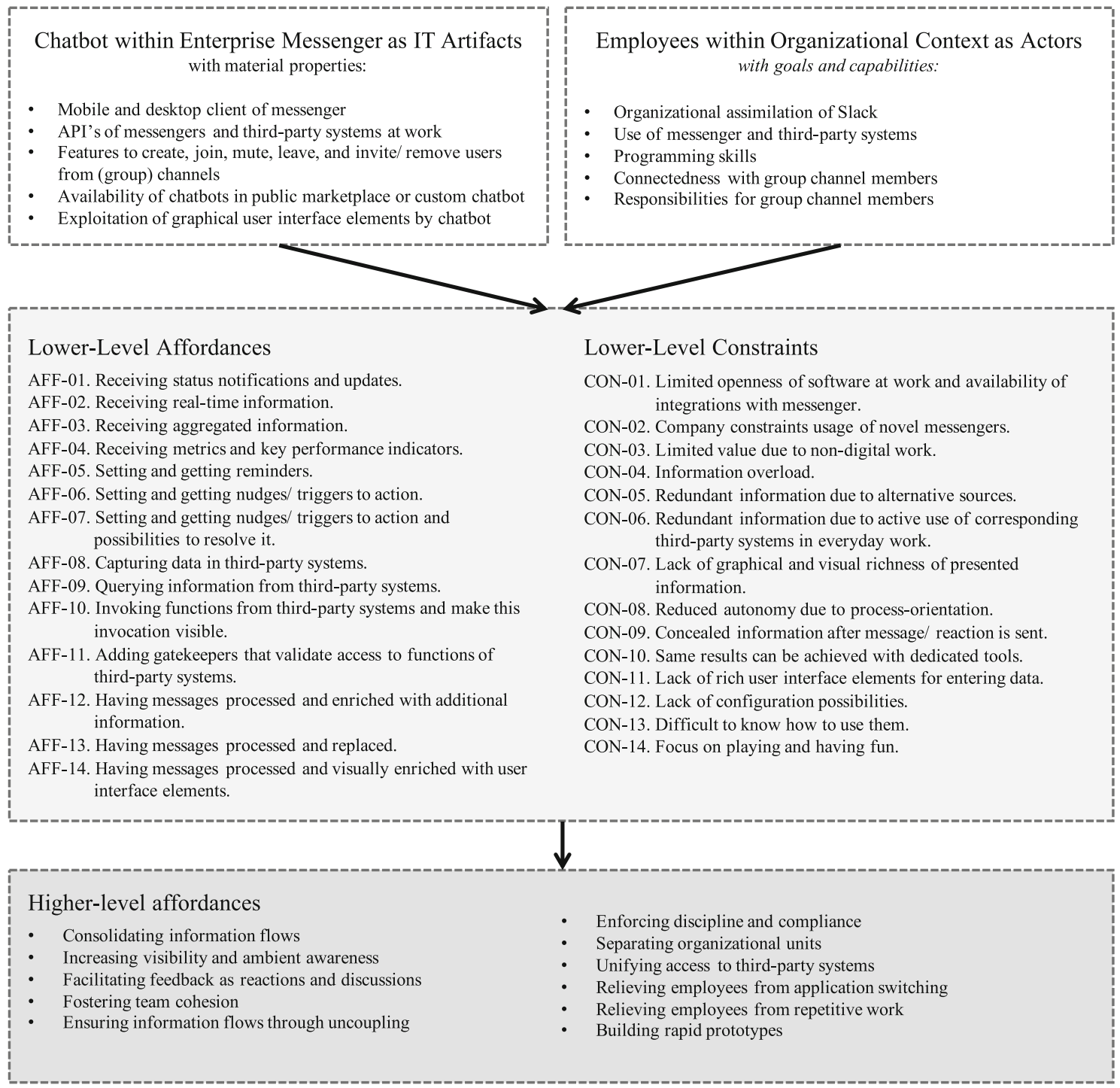

Fig. 7 Contextual emergence of lower-level and higher-level affordances and constraints

\section{Category 1. Affordances and constraints related to receiving messages}

First, four affordances (see AFF-01 to AFF-04 in Table 2) emerge from chatbots that post messages into conversational channels with information from third-party systems and outcomes of automated workflows.

Higher level affordances Being able to integrate messages from multiple chatbots and humans in one place affords to consolidate and unify communication flows. "I know that all the important things that I have to be aware of end up [in the corresponding Slack channel]" (Interview \#15). This yield "a tremendous saving of time. Instead of gathering information up from emails and hundreds of third-party systems, I have everything at a glance"
(Interview \#15). "I see everything that happened over night, this is cool because conversations are sorted by project [channel] and I can go through by priority" (Interview \#5). Furthermore, it relieves employees from "switching between monitors and programs all the time" (Interview \#16) and "it redeems from informing someone that you have pushed [source code], because it happens automatically" (Interview \#1). Thus, affording to automate information flows and, consequently, to uncouple information flows from individual employees.

In addition, our interviewees expect that actualizing Affordances 1.1 to 1.4 can collectively lead to increased ambient awareness. Chatbots "help team members to be more aware of the load they are putting on others" (Interview \#4). An interviewee perceived that receiving build and continuous integration updates brings business and technology closer 
Table 2 Affordances related to receiving information and outcomes of automated workflows

\begin{tabular}{|c|c|c|}
\hline Affordance & Context and outcome of affordance actualization & Card sorting phase $2 \mathrm{~b} \& 3$ \\
\hline $\begin{array}{l}\text { Receiving status notifications } \\
\text { and updates (AFF-01) }\end{array}$ & $\begin{array}{l}\text { Context (Alpha, Beta, Delta, Epsilon, Eta). In software developing } \\
\text { teams, chatbots were used to post status updates from version control } \\
\text { systems (e.g., Git), issue tracking systems (e.g., Jira), build and } \\
\text { continuous integration systems (e.g., TeamCity). } \\
\text { Outcome. Status update (e.g., source code was committed, issue was } \\
\text { resolved, new version was deployed) is automatically posted to a } \\
\text { team or dedicated separate channel. } \\
\text { Context (Alpha). Outgoing social media posts are officially posted by the } \\
\text { responsible employees but relevant for all. } \\
\text { Outcome. Outgoing social media communication is posted to a general } \\
\text { channel. }\end{array}$ & $\begin{array}{l}\text { 1.94 avg. sort position ( } 1 \text { as most } \\
\text { relevant of } 4 \text { cards) in Phase } 2 b \text {. } \\
\text { 1.04 avg. } \\
\text { Q-Sort ranking (from }+2 \text { to }-2) \text { in } \\
\text { Phase 3. }\end{array}$ \\
\hline $\begin{array}{l}\text { Receiving real-time informa- } \\
\text { tion (AFF-02) }\end{array}$ & $\begin{array}{l}\text { Context (Eta). Error messages of different systems are often spread } \\
\text { across various log files, which hinders debugging. } \\
\text { Outcome. Major error messages are passed to a channel to debug in } \\
\text { chronological order. } \\
\text { Context (Theta). To better understand individual test users, chatbots } \\
\text { were used to trace a customer along a buying process. } \\
\text { Outcome. Each step of a customers' journey is posted to a Slack channel. }\end{array}$ & $\begin{array}{l}\text { 2.82 avg. sort position ( } 1 \text { as most } \\
\text { relevant of } 4 \text { cards) in Phase } 2 b \text {. } \\
\text { 1.32 avg. } \\
\text { Q-Sort ranking (from }+2 \text { to }-2) \text { in } \\
\text { Phase } 3 .\end{array}$ \\
\hline $\begin{array}{l}\text { Receiving aggregated } \\
\text { information (AFF-03) }\end{array}$ & $\begin{array}{l}\text { Context (Beta). Fetching information from various sources (e.g., Kanban } \\
\text { board) and preparing a structured meeting agenda for status meetings } \\
\text { is a repetitive task that is done by a chatbot. } \\
\text { Outcome. Automatically generated meeting agenda is posted to project } \\
\text { channel. } \\
\text { Context (Alpha). Gathering lunch menus of nearby cafeterias is done by } \\
\text { a chatbot. } \\
\text { Outcome. Automatically fetched meals are posted to channel. }\end{array}$ & $\begin{array}{l}\text { 2.53 avg. sort position ( } 1 \text { as most } \\
\text { relevant of } 4 \text { cards) in Phase } 2 \mathrm{~b} \text {. } \\
\mathbf{0 . 8 9} \text { avg. } \\
\text { Q-Sort ranking (from }+2 \text { to }-2) \text { in } \\
\text { Phase } 3 \text {. }\end{array}$ \\
\hline $\begin{array}{l}\text { Receiving metrics and key } \\
\text { performance indicators } \\
\text { (AFF-04) }\end{array}$ & $\begin{array}{l}\text { Context (Beta). Velocity measure as amount of functionality scrum } \\
\text { teams deliver is repeatedly calculated by a chatbot. } \\
\text { Outcome. An overview of the relative movement of each project is } \\
\text { posted to a channel. } \\
\text { Context (Epsilon, Eta, Theta). Analytics data and reviews/ratings from } \\
\text { app stores are fetched by chatbots. } \\
\text { Outcome. This feedback to the own product or service is posted to Slack } \\
\text { (either immediately or aggregated). }\end{array}$ & $\begin{array}{l}\mathbf{2 . 6 5} \text { avg. sort position ( } 1 \text { as most } \\
\text { relevant of } 4 \text { cards) in Phase } 2 \mathrm{~b} \text {. } \\
\mathbf{0 . 5} \text { avg. } \\
\text { Q-Sort ranking (from }+2 \text { to }-2 \text { ) in } \\
\text { Phase } 3 \text {. }\end{array}$ \\
\hline
\end{tabular}

together. "I see where we stand, [...], what the current version contains, and new features that we have developed [relevant] for sales - so, it certainly creates proximity to the software development team" (Interview \#3). Also, within teams, "I notice what is going on in other repositories [from my team] where I'm not directly involved"' (Interview \#1).

Moreover, teams created dedicated channels, e.g., a channel for major errors, where "I know exactly, if something goes wrong, then, we really have a major problem which absolutely has to be resolved" (Interview \#15). As described by the interviewees, this nicely coalesces with the possibility to react to any posted content (e.g., with emojis, replies). For the interviewees, this is how it affords them facilitating discussions, as well as faster and shorter feedback cycles, which "is key in today's world. When a developer gets aware of what user $\mathrm{x}$ thinks about our product at the same time as I do, then, the communication simply flows much faster. And this is something we cannot achieve differently, even if I would tell it in every daily [Scrum meeting], which would be completely inefficient" (Interview \#13). Here, the affordance to uncouple such information flows from individual employees was described with positive side effects, namely, "it also feels better [when the information of bad product reviews comes from the bot instead of the boss]" (Interview \#13).

Finally, posting metrics and key performance indicators makes undisciplined behavior and violations against reference values visible (see Fig. 8). This enables to enforce discipline and compliance, because "they could see the problems" (Interview \#4). Accordingly, possibilities to shape the organizational culture emerge.

Constraints By having machines post messages to channels, a risk of producing information overload exists. It "is basically a question of [applying the] push or pull principle... do I really have to know when someone builds, or do I look it up when I need it?" (Interview \#12). Therefore, integrating chatbots that post messages has to be well thought out, to prevent the messages from becoming constraining. In fact, "messages regarding the build processes were only interesting in $20 \%$ of the time" (Interview \#12). Our results indicate that the way 


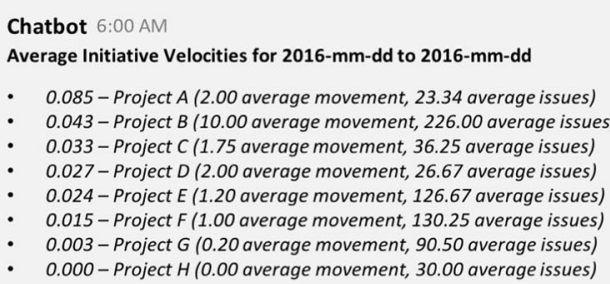

Chatbot 7:30 AM

Here is the latest daily digest for 2016-mm-dd to 2016-mm-dd

Your assigned issues

- Issue (https://github.com/issue url)

Your stale issues: Please update theses issues!

- Issue (https://github.com/issue url)

Your unassigned pull requests: Recruit someone to merge your PR's ! - Pull Request (https://github.com/pull url)

Fig. 8 Chatbot related to Affordance AFF-04 and AFF-06 (created based on screenshots from Beta)

incoming chatbot messages are perceived (e.g., as an affordance or a constraint) strongly depends on the individual workflow and current context, which is not necessarily aligned with the other subscribers of a channel. Project status meeting agendas generated from metadata are perceived as "semi-interesting because I spend at least some hours on that project every day, but for people that are less involved it is very useful to run a meeting" (Interview \#5). "These are my daily working tools, I don't need an integration that tells me hey your project has reached $50 \%$ of the billable hours, because [as a manager] I'm using this software every day" (Interview \#12). This plays well together with the possibility of Slack to mute individual channels. Therefore, "we have thought about creating a separate channel for our chatbot and if it annoys you, then you can simply leave or mute the channel" (Interview \#1). However, "if a separate channel is used, then, you risk not being able to reach all team members anymore. It has to be balanced how important it is that everyone sees it" (Interview \#1). "If the channel is relatively important, [...], then you cannot mute it" (Interview \#5). Oftentimes, "it depends on your job role, personally I have muted many of the channels in which chatbots regularly post messages except for the project [channels] where I'm responsible for. I have two projects where I as the architect have the technical responsibility and do have to know what my software developers commit and what bug reports are created" (Interview \#5).

Interviewees expect to be able to "create some sort of digest, which means that I would be able to choose getting information [i.e., chatbot messages for a certain channel] only once per day, week, only during nights or just if it matches certain filter criteria" (Interview \#15). Some interviewees perceived incoming information to be redundant, and thus, distracting. "At a certain point I had to say okay if I get this notification also here [within Slack] and I have already seen it before [notifications of the third-party system on mobile and desktop], then it distracts more than it is useful" (Interview \#3). Furthermore, the textual representation of information was perceived as a constraint. "I like having information graphically prepared” (Interview \#15).

\section{Category 2. Affordances and constraints related to getting triggers}

Next, three affordances (AFF-05 to AFF-07 in Table 3) ground in the potential of chatbots to allow setting and getting triggers.

Table 3 Affordances related to getting and setting triggers and reminders

\begin{tabular}{|c|c|c|}
\hline Affordance & Context and Outcome of Affordance Actualization & Card Sorting Phase $2 \mathrm{~b} \& 3$ \\
\hline $\begin{array}{l}\text { Setting and getting reminders } \\
(\text { AFF-05) }\end{array}$ & $\begin{array}{l}\text { Context (Beta, Theta). The default Slack Bot was used to prevent from } \\
\text { forgetting to answer an incoming message. } \\
\text { Outcome. Reminders to answer are posted to Slack channel at a } \\
\text { chosen time. } \\
\text { Context (Alpha, Delta). Chatbots were used to avoid that community } \\
\text { tasks such as cleaning the office or periodic tasks such as daily } \\
\text { scrum meetings are forgotten. } \\
\text { Outcome. Reminders of expectable events are posted to Slack } \\
\text { channel. }\end{array}$ & $\begin{array}{l}\text { 2.29 avg. sort position (with } 1 \text { being the } \\
\text { most relevant of } 3 \text { cards) in Phase } 2 \mathrm{~b} \text {. } \\
\mathbf{0 . 9 3} \text { avg. Q-Sort ranking (from }+2 \text { to }-2 \text { ) } \\
\text { in Phase } 3 \text {. }\end{array}$ \\
\hline $\begin{array}{l}\text { Setting and getting nudges/ triggers } \\
\text { to action (AFF-06) }\end{array}$ & $\begin{array}{l}\text { Context (Beta). Monitoring potential problems areas (e.g., unassigned } \\
\text { pull requests, unresolved issues) is often annoying for managers } \\
\text { and is therefore done by a chatbot. } \\
\text { Outcome. Nudging employees to improve by creating and posting a } \\
\text { daily digest with commitments and problem areas until they are fixed. }\end{array}$ & $\begin{array}{l}\text { 2.00 avg. sort position (with } 1 \text { being the } \\
\text { most relevant of } 3 \text { cards) in Phase } 2 \mathrm{~b} \text {. } \\
\mathbf{0 . 9 3} \text { avg. Q-Sort ranking (from }+2 \text { to }-2 \text { ) } \\
\text { in Phase } 3 \text {. }\end{array}$ \\
\hline $\begin{array}{l}\text { Setting and getting nudges/ triggers } \\
\text { to action with possibilities to re- } \\
\text { solve it (AFF-07) }\end{array}$ & $\begin{array}{l}\text { Context (Gamma). Time tracking is a common task of employees. } \\
\text { However, it often gets forgotten and is difficult to do later. To } \\
\text { prevent this, a chatbot is used. } \\
\text { Outcome. Reminders to capture working hours are posted and can be } \\
\text { resolved by responding to the chatbot. }\end{array}$ & $\begin{array}{l}\text { 1.71 avg. sort position (with } 1 \text { being the } \\
\text { most relevant of } 3 \text { cards) in Phase } 2 \mathrm{~b} \text {. } \\
\mathbf{0 . 9 6} \text { avg. Q-Sort ranking (from }+2 \text { to }-2 \text { ) } \\
\text { in Phase } 3 \text {. }\end{array}$ \\
\hline
\end{tabular}


Higher level affordances Setting reminders was perceived as affording automation of repetitive message flows and, thus, to relieves employees from repetitive work. "So that not every day someone has to write [to remind of the daily scrum meeting]" (Interview \#3). Also, getting reminded to perform some task together with the potential to resolve it, was perceived as a chance to increase efficiency. "If I get reminded every evening [to capture the hours I worked], then everything is done in 3 seconds" (Interview \#7). "I see a lot of potential for activities which are made regularly, but not every day" (Interview \#6).

Furthermore, it was perceived as enforcing team discipline and compliance. As such, it provides "advice in accordance with our development culture" (Interview \#4). For example, it includes problem areas and undisciplined behavior, such as unassigned pull requests or unassigned issues. Thus, it affords to shape the organizational culture. An interviewee stated that "sometimes something goes forgotten and then you get daily a reminder" and has compared it to previous situations in which "a project manager had this [...] job to run after all to say why are there no labels and why is this like that" (Interview \#5).

On the one hand, such chatbots are perceived as tools to relieve managers from repetitive micromanagement tasks, which are then executed automatically in a consistent and exact way. "It is mainly a tool that helps our managers to enforce discipline. For me as a developer it is much less useful than for him" (Interview \#5). On the other hand, the technology is perceived as an actor that "keeps its eyes on us and barks when it saw a slip in discipline" (Interview \#4). However, "as soon as it becomes quantitative, employees begin to play out the whole thing. If you tell me one gets points for each movement on the [Kanban] board, then, I can create micro issues and move them through" (Interview \#5).

Constraints On the one hand, certain teams "want to keep up the degree of freedom so that we do not really want to squeeze ourselves into processes" (Interview \#16). On the other hand, many bot-specific constraints were perceived, such as a lack of usability. The chatbot "only asks, I give the input and then it disappears. It should also be visually recognizable what I have entered. [...] But basically I think it is good when you are able to directly resolve things" (Interview \#6). As a consequence, other technical artifacts often afford similar goal-oriented actions, e.g., "my calendar reminds me as well with a popup" (Interview \#6).

Furthermore, interviewees expected "an official communication to everyone or for a certain group that informs what we want to achieve, and then that applies to all. [...] And that did not exist in this case, there was no communication. Suddenly, there was a bot who has asked me now and then what I do" (Interview \#6).

\section{Category 3. Affordances and constraints related to queries and invocations}

Additional four affordances (AFF-08 to AFF-11 in Table 4) are reveal potentials to query and invoke functionality of thirdparty systems.

Higher level affordances Being able to capture data into thirdparty systems directly from Slack was perceived as valuable to achieve everything in one place, but not necessarily act as a substitute for the third-party systems. "We do not want to replace it, we still open Trello but we have the possibility to capture tasks [directly within Slack]. This makes it much easier, because you can mark something, copy, and quickly pass it over [to Trello]" (Interview \#16). Accordingly, it relieves employees from application switching.

Moreover, being able to query and invoke functionality from third-party systems was perceived as a possibility for rapidly building prototypes without having to develop and introduce yet another employee-facing user interface. It is useful "for new features that we develop and try out. So, you can prototype faster" (Interview \#5). It was also used to provide a broader audience with access to third-party systems so "that they have an interface to pull information easily [from the database]" (Interview \#15).

Using commands (or natural language) to invoke functionality within Slack does not only afford the accomplishment of the invocation itself, it also simultaneously affords visibility to all members of the team channel. For example, when directly deploying from the project channel within Slack, then, the information about who is deploying when is disclosed. "It saves to say I now have pushed a new version, because it happens automatically" (Interview \#1). Hence, it affords automation and consequently ensures certain information flows. At the same time, invocations become traceable and searchable in real-time, thus, facilitating ambient awareness within the teams. "Usually just before 7, I open Slack and see what my colleagues in India have already done" (Interview \#5). In turn, reactions and discussions enable fast feedback cycles.

Furthermore, possibilities to introduce gatekeepers arise, e.g., the default Slack bot tracks the status of people and intervenes when someone sends a message to ask if Slack should really push a notification, even though the user status is set on "do not disturb". This is helpful "in general to reduce noise, like a personal assistant as a gatekeeper" (Interview \#5). In addition, invocations might be verified, delayed or prevented. In fact, chatbots afford to separate different organizational units (e.g., developers from the production environments of customers) and glue them back together.

Constraints In the long run, querying information within Slack was found to be constraining, as compared to dedicated tools. "The company has grown now. For the beginning it was 
Table 4 Affordances related to queries and invocations within Slack channels

\begin{tabular}{|c|c|c|}
\hline Affordance & Context and outcome of affordance actualization & Card sorting phase $2 \mathrm{~b} \& 3$ \\
\hline Capturing data (AFF-08) & $\begin{array}{l}\text { Context (Epsilon, Theta). When using Kanban boards for project } \\
\text { management (e.g., Trello), chatbots help to capture data. } \\
\text { Outcome. Command adds cards to Trello boards from within Slack } \\
\text { channel. }\end{array}$ & $\begin{array}{l}2.82 \text { avg. sort position (with } 1 \text { being the } \\
\text { most relevant of } 4 \text { cards) in Phase } 2 \mathrm{~b} \text {. } \\
\text { 0.39 avg. Q-Sort ranking (from }+2 \text { to }-2 \text { ) } \\
\text { in Phase } 3 \text {. }\end{array}$ \\
\hline Querying information (AFF-09) & $\begin{array}{l}\text { Context (Eta). Querying databases requires corresponding skills. To } \\
\text { rapidly enable employees from sales to execute predefined queries, } \\
\text { chatbots were used. } \\
\text { Outcome. Available commands for everyone within the actualized } \\
\text { channel to query the latest data. }\end{array}$ & $\begin{array}{l}\text { 2.41 avg. sort position (with } 1 \text { being the } \\
\text { most relevant of } 4 \text { cards) in Phase } 2 \mathrm{~b} \text {. } \\
\text { 0.10 avg. Q-Sort ranking (from }+2 \text { to }-2 \text { ) } \\
\text { in Phase } 3 \text {. }\end{array}$ \\
\hline $\begin{array}{l}\text { Invoking functionality and } \\
\text { making this invocation } \\
\text { visible (AFF-10) }\end{array}$ & $\begin{array}{l}\text { Context (Beta). Status reports with repetitive elements can be partially } \\
\text { generated by a chatbot to limit the required human input to writing a } \\
\text { summary. } \\
\text { Outcome. Available commands to partially generate status reports. } \\
\text { Context (Alpha, Delta). Instead of creating video conference (e.g., } \\
\text { join.me, appear.in) followed by sharing access details, bots are used to } \\
\text { achieve both in one step. } \\
\text { Outcome. Available commands to create and share access to a video } \\
\text { conference within the corresponding channel. } \\
\text { Context (Beta). Instead of initiating software deployments from the } \\
\text { isolated console, chatbots are harnessed to initiate deployments within } \\
\text { Slack channels (e.g., the corresponding project channel). } \\
\text { Outcome. Available commands to initiate deployment within Slack } \\
\text { channels, which makes it is visible and traceable. }\end{array}$ & $\begin{array}{l}\text { 2.06 avg. sort position (with } 1 \text { being the } \\
\text { most relevant of } 4 \text { cards) in Phase } 2 \mathrm{~b} \text {. } \\
\mathbf{0 . 4 3} \text { avg. Q-Sort ranking (from }+2 \text { to }-2 \text { ) } \\
\text { in Phase } 3 \text {. }\end{array}$ \\
\hline Adding gatekeepers (AFF-11) & $\begin{array}{l}\text { Context (Beta). Due to separation of duties, developers were separated } \\
\text { from production environments with sensitive data and glued back } \\
\text { together using chatbots. } \\
\text { Outcome. Authorized legal responsible uses chatbot to confirm and } \\
\text { trigger the provisioning of software to customer environments. }\end{array}$ & $\begin{array}{l}\text { 2.71 avg. sort position (with } 1 \text { being the } \\
\text { most relevant of } 4 \text { cards) in Phase } 2 \mathrm{~b} \text {. } \\
\mathbf{0 . 1 0} \text { avg. Q-Sort ranking (from }+2 \text { to }-2 \text { ) } \\
\text { in Phase } 3 \text {. }\end{array}$ \\
\hline
\end{tabular}

relatively simple and also easily possible [for the sales team to query data within Slack], but the more customers and the bigger the customers, you need proper tools for data processing, aggregation, and evaluation" (Interview \#15).

Passing parameters with commands to invoke functionality was also perceived as constraining. "We then started to build our own tools, because it is annoying to pass numerous parameters with commands and they [i.e., existing Slack apps and integrations] are often not really configurable" (Interview \#15).

Non-technical interviewees often expressed difficulties to obtain an idea about how certain Slack apps and integrations may create value. "What is missing are cases that point out how teams work with this and that and thus showing how it [i.e., the Slack app and integration] creates added value" (Interview \#3).

\section{Category 4. Affordances and constraints related to enriching messages}

Finally, three affordances (AFF-12 to AFF-14 in Table 5) relate to enriching outgoing messages of human actors.

Higher level affordances In the majority of the considered organizational contexts, variations of chatbots enrich messages with appropriate gif images to increase the expressive power of textual communication. Using them affords to foster team cohesion, spirit and fun, because "especially in a distributed team, it is relatively difficult to promote interpersonal communication" (Interview \#5). Assuming that "you have forgotten something, then, a gif is shown from Barack Obama where he drops his microphone. This is just to promote interpersonal communication and to not having quite such a dry business context" (Interview \#5). It is "just for fun, but I think to a relatively large extent, it helps to keep the people together" (Interview \#15).

Having messages processed and enriched with additional information, was found to play well together with the basic functionality of Slack, e.g., by automatically importing files posted as links within a message to enable searches on it. Access to files can be simplified by automatically sharing it with channel members. Overall, it affords linking and consolidating third-party systems within Slack, e.g., traditional enterprise systems such as customer relationship management systems.

Constraints It was stated that "much is about playing a bit and a bit of fun, but what is the real value added?" (Interview \#3). Accordingly, the use has decreased over time. "When we introduced Slack, it almost exploded for three days, because for 
Table 5 Affordances related to the enrichment of messages

\begin{tabular}{|c|c|c|}
\hline Affordance & Context and outcome of affordance actualization & Card sorting phase $2 \mathrm{~b} \& 3$ \\
\hline $\begin{array}{l}\text { Having messages processed and } \\
\text { enriched with content } \\
\text { (AFF-12) }\end{array}$ & $\begin{array}{l}\text { Context (Alpha, Delta, Theta). Teams working with file management } \\
\text { services (e.g., Dropbox, Google Drive) use apps and integrations to } \\
\text { extend the functional scope. } \\
\text { Outcome. Posted messages with links to files are processed (e.g., } \\
\text { imported) and enriched (e.g., meta-information). }\end{array}$ & $\begin{array}{l}1.18 \text { avg. sort position (with } 1 \text { being the } \\
\text { most relevant of } 2 \text { cards) in Phase } 2 b \text {. } \\
\text { 0.29 avg. Q-Sort ranking (from }+2 \text { to }-2 \text { ) } \\
\text { in Phase } 3 \text {. }\end{array}$ \\
\hline $\begin{array}{l}\text { Having messages processed and } \\
\text { replaced (AFF-13) }\end{array}$ & $\begin{array}{l}\text { Context (Beta, Delta, Eta). As a response to the limiting interpersonal } \\
\text { communication with textual messages, chatbots such as Giphy provide } \\
\text { potentials to increase the expressive power of textual messages. } \\
\text { Outcome. Using the available commands together with a keyword } \\
\text { replaces the message with a topic-related gif image. }\end{array}$ & $\begin{array}{l}\text { 1.82 avg. sort position (with } 1 \text { being the } \\
\text { most relevant of } 4 \text { cards) in Phase } 2 b \text {. } \\
\text { 0.29 avg. Q-Sort ranking (from }+2 \text { to }-2 \text { ) } \\
\text { in Phase } 3 \text {. }\end{array}$ \\
\hline $\begin{array}{l}\text { Having messages processed and } \\
\text { visually enriched with user } \\
\text { interface elements (AFF-14) }\end{array}$ & $\begin{array}{l}\text { Context (Iota, Kappa, Lambda, } \mathrm{Mu}, \mathrm{Nu} \text { ). Gathering feedback within } \\
\text { teams by creating short polls and surveys is a frequent task of } \\
\text { employees. However, when doing so by asking a simple question it is } \\
\text { difficult to keep an overview of replies. } \\
\text { Outcome. Polls are created within a channel of choice by employees can } \\
\text { vote/ participate by using buttons, while the votes are visually aggregated. }\end{array}$ & $\begin{array}{l}\text { Added after Phase } 2 \mathrm{~b} \text {. } \\
\mathbf{0 . 8 6} \text { avg. Q-Sort ranking (from }+2 \text { to }-2 \text { ) } \\
\text { in Phase } 3 \text {. }\end{array}$ \\
\hline
\end{tabular}

every word, you found [someone posting] a gif, which has led to whole conversations composed of GIFs, but this is not useful, just funny, what in turn is fine as well" (Interview \#11).

\section{Understanding perceptional similarities and differences among employees}

Conducting physical card sorting as part of the interviews of Phase $2 \mathrm{~b}$ and the subsequent Q-Methodology study in Phase 3 reveals patterns of how employees weigh the perception of affordances against the perception of constraints that emerge from chatbots within enterprises. Specifically, our empirical data highlights both similarities as well as differences among employees in the perception of chatbots within enterprises. Perceptional similarities can be summarized along two dimensions.

First, we find that on average employees perceive affordances related to receiving messages from thirdparty systems (i.e., Category 1) as higher compared to all other affordances. This finding is true for both conducted card sorting studies (see the heatmap of values from Phase 2 and Phase 3 in Appendix). Though we explored the use of alternative messenger platforms aside from Slack (i.e., Microsoft Teams and Telegram), the identified affordances and constraints within the enterprise context remained rather constant. However, aside from chatbots, Microsoft Teams provides tabs as an alternate form of messenger integrations with third-party systems, which offer similar affordances, e.g., both tabs as well as chatbots may be used to receive metrics and key performance indicators within Microsoft Teams (Interviews \#26 and \#27).

Second, throughout the participants of the Q-Study, the relevance of chatbots is assessed as highest in group channels that relate to projects at work (see Fig. 9). In contrast, the variance in the assessed relevance of chatbots was much higher for all other types of group channels. In fact, this variance in the relevance of certain channels is also reflected in the qualitative interviews. For example, an interviewee explained that inter-organizational channels became relevant when they moved to a new co-working space that promoted such a channel (Interview \#2). We find that changes of the socio-technical context over time (e.g., hiring new co-workers, changing the office location, introducing new third-party systems) alter the coordination needs and, thus, the perception of chatbots by employees. In turn, this leads over to the perceptional differences studied in our Q-Methodology study.
Fig. 9 Relevance of chatbot integrations per channel type

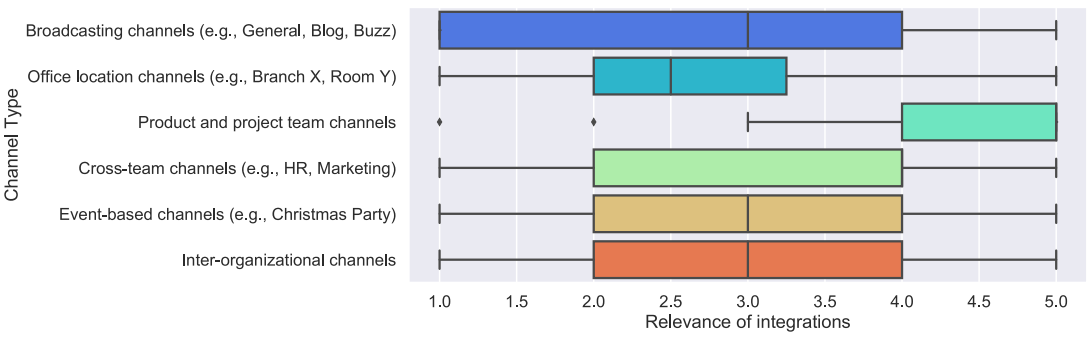


Our results highlight five factors that represent perceptional differences among employees in the form of five distinct viewpoints on chatbots. Specifically, we find that chatbots within enterprise messengers are viewed (1) as operational assistants, (2) as central information hubs, (3) as difficult to use black boxes and worse alternatives to dedicated tools, (4) as shadow IT in restrictive and closed legacy environments, and (5) as spammy and process-enforcing burden. In the following we elaborate each of the five viewpoints and present the idealized Q-Sort in Figs. 10, 11, 12, 13, and 14.

\section{Viewpoint 1 - as an operational assistant at a central point of team coordination}

The first viewpoint reveals a group of employees that perceive chatbots within enterprise messengers as operational assistants that help them invoking functionality from thirdparties, setting and getting reminders within channels, receiving real-time information and having messages processed as well as visually enriched (e.g., in the form of polls): "Sometimes we need to create a poll to decide about some things as a team. That's why it's very useful that we can do it in here where all team members have access to and can come back to see the result" (Participant 19). In line with the identified higher-level affordance of relieving employees from application switching, one participant commented on the Q-Sort as follows: "It is particularly helpful, because I do not need to open a new program and, hence, I can save a lot of time" (Participant 8). A second thought pattern that is shared among this group of employees is the value that arises from the central point of team coordination: "If one starts a deployment to production, another needs to confirm in Slack. Once it's done, a quality assurance engineer needs to confirm that everything is ok. All information of a deployment is easily visible in the Slack channel and one can comment on it" (Participant 15). Accordingly, the Q-Sort shows that employees of this group strongly disagree with the assertion that information is repetitive due to alternate systems such as email. Comments reveal that organizations of this group of employees have mostly replaced emails: "I'm often using Slack instead of Email” (Participant 5).

\begin{tabular}{|c|c|c|c|c|}
\hline-2 & -1 & 0 & 1 & 2 \\
\hline $\begin{array}{l}\text { CON-03 Most of my work is not } \\
\text { digital. }\end{array}$ & $\begin{array}{l}\text { CON-09 Information is concealed } \\
\text { after I sent the message. }\end{array}$ & $\begin{array}{l}\text { AFF-09 Querying information from } \\
\text { third-party systems within } \\
\text { channels. }\end{array}$ & $\begin{array}{l}\text { AFF-07 Setting and getting nudges/ } \\
\text { triggers to action and } \\
\text { possibilities to resolve it within } \\
\text { the channel. }\end{array}$ & $\begin{array}{l}\text { AFF-14 Having messages processed } \\
\text { and visually enriched with user } \\
\text { interface elements. }\end{array}$ \\
\hline $\begin{array}{l}\text { *ON-05 Repetitive information since } \\
\text { I often already know the } \\
\text { information from alternative } \\
\text { sources such as notifications. }\end{array}$ & $\begin{array}{l}\text { CON-13 It is difficult to know how } \\
\text { to use them. }\end{array}$ & $\begin{array}{l}\text { AFF-12 Having messages processed } \\
\text { and enriched with additional } \\
\text { information. }\end{array}$ & $\begin{array}{l}\text { AFF-06 Setting and getting nudges/ } \\
\text { triggers to action within channels. }\end{array}$ & $\begin{array}{l}\text { AFF-02 Receiving real-time } \\
\text { information from third-party } \\
\text { systems within channels. }\end{array}$ \\
\hline $\begin{array}{l}\mathrm{CON}-02 \mathrm{My} \text { company constraints the } \\
\text { usage of such messengers. }\end{array}$ & $\begin{array}{c}\text { CON-04 They lead to information } \\
\text { overload. }\end{array}$ & $\begin{array}{l}\text { AFF-03 Receiving aggregated } \\
\text { information from third-party } \\
\text { systems within channels. }\end{array}$ & $\begin{array}{l}\text { AFF-04 Receiving metrics and key } \\
\text { performance indicators from } \\
\text { third-party systems within } \\
\text { channels. }\end{array}$ & $\begin{array}{l}\text { AFF-10 Invoking functions from } \\
\text { third-party systems and make this } \\
\text { invocation visible within channels. }\end{array}$ \\
\hline \multirow[t]{5}{*}{$\begin{array}{l}\mathrm{CON}-14 \text { It is more about playing and } \\
\text { having fun than real value added. }\end{array}$} & $\begin{array}{l}\text { CON-06 Repetitive information since } \\
\text { I use these systems in my everyday } \\
\text { work. }\end{array}$ & $\begin{array}{l}\text { CON-11 Lack of rich user interface } \\
\text { elements for entering data. }\end{array}$ & $\begin{array}{l}\text { CON-01 Most software at work is not } \\
\text { open enough and has limited } \\
\text { integrations with messenger. }\end{array}$ & $\begin{array}{l}\text { AFF-05 Setting and getting } \\
\text { reminders within channels. }\end{array}$ \\
\hline & $\begin{array}{l}\text { CON-08 They introduce } \\
\text { process-orientation and reduce my } \\
\text { autonomy. }\end{array}$ & $\begin{array}{l}\text { AFF-11 Adding gatekeepers that } \\
\text { validate access to functions of } \\
\text { third-party systems. }\end{array}$ & $\begin{array}{l}\text { AFF-13 Having messages processed } \\
\text { and replaced. }\end{array}$ & \\
\hline & $\begin{array}{l}\text { CON-10 I can achieve the same } \\
\text { results with dedicated tools. }\end{array}$ & $\begin{array}{l}\text { AFF-08 Capturing data in } \\
\text { third-party systems from within } \\
\text { channels. }\end{array}$ & $\begin{array}{l}\text { AFF-01 Receiving status } \\
\text { notifications and updates from } \\
\text { third-party systems within } \\
\text { channels. }\end{array}$ & \\
\hline & & $\begin{array}{l}\text { CON-07 The presented information } \\
\text { lacks graphical and visual } \\
\text { richness. }\end{array}$ & & \\
\hline & & $\begin{array}{l}\text { CON-12 Lack of configuration } \\
\text { possibilities without programming } \\
\text { customized integrations. }\end{array}$ & & \\
\hline
\end{tabular}

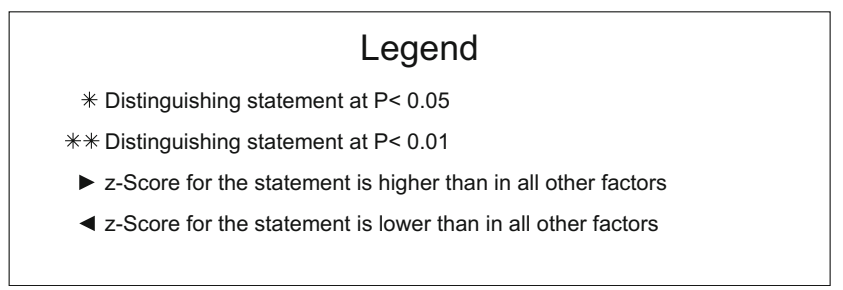

Fig. 10 Idealized Q-sort for viewpoint 1 - operational assistant 


\section{Viewpoint 2 - as a central information hub for the coordination of human and machine work}

The second viewpoint highlights the value of chatbots in contemporary enterprise messengers to keep pace with what is going on at work by automating status notifications and updates. "When I log on, I quickly see what I've missed" (Participant 21). "It is super convenient to have all notifications in one place. I don't like to check all tools every day to see if something has come up" (Participant 16). In line with the very nature of "instant" messengers to facilitate real-time information between humans, chatbots extend this possibility with real-time information from third-party systems: "Issues and GitHub commits are reported live and give an overview of what is currently going on" (Participant 28). Similar to employees that perceive chatbots as operational assistants, members of this group heavily rely on chatbots in their work practices: "When I know that Slack will send me a message when my build fails, then I don't check the other tools. Thus, the confidence in the integration must be so good that you no longer have to check the other tool" (Participant 2). A further perspective that is taken is the that information from humans and machines come together in one place: "So far I found no other tool that allows me to integrate information from all other systems and, at the same time, can be used as a communication channel" (Participant 16). Following this line of thought suggests that employees like switching back and forth between passively following work activities and actively coordinate work: "With HipChat it is possible to collect all information about a topic and to discuss problems (e.g., build errors) immediately. That's why I notice HipChat notifications more than mail notifications." (Participant 24). Consequently, this viewpoint goes along with task dependencies: "It raises awareness when someone contributed or finished a part of work that is relevant for one's own task" (Participant 5).

\section{Viewpoint 3 - as a difficult to use black box and a worse alternative to dedicated tools}

The third viewpoint reflects the opinion of a critical group of users that shares concerns regarding usability and that is skeptical that chatbots provide an added value in comparison to dedicated tools with richer user interfaces. On the one hand, the Q-Sort highlights agreement with constraints in the ease of use of chatbots that are integrated into the conversational thread: "most of the integrations I don't use, because it's not worth the effort, I prefer to use the original application" (Participant 20). On the other hand, information is concealed after messages are exchanged: "It's very hard to keep track of information, there is no system, only the chronology of the messages" (Participant 20)". As such, the perspective of this group is in contrast to the previous two viewpoints, even though all three groups compare chatbots with alternate tools: "probably I could achieve the same result with other tools, but not in the same time, e.g., if I would have to check one system for my alerts, talk to my colleagues in another tool and, then, analyze it further in a third tool, I would need much more time" (Participant 11). Nevertheless, this rather skeptical

\begin{tabular}{|c|c|c|c|c|}
\hline-2 & -1 & 0 & 1 & 2 \\
\hline $\begin{array}{l}\text { CON-06 Repetitive information since } \\
\text { I use these systems in my everyday } \\
\text { work. }\end{array}$ & $\begin{array}{l}\text { CON-01 Most software at work is not } \\
\text { open enough and has limited } \\
\text { integrations with messenger. }\end{array}$ & $\begin{array}{c}\text { AFF-12 Having messages processed } \\
\text { and enriched with additional } \\
\text { information. }\end{array}$ & $\begin{array}{c}\text { AFF-07 Setting and getting nudges/ } \\
\text { triggers to action and } \\
\text { possibilities to resolve it within } \\
\text { the channel. }\end{array}$ & $\begin{array}{l}\text { AFF-01 Receiving status } \\
\text { notifications and updates from } \\
\text { third-party systems within } \\
\text { channels. }\end{array}$ \\
\hline $\begin{array}{l}\text { CON-08 They introduce } \\
\text { process-orientation and reduce my } \\
\text { autonomy. }\end{array}$ & $\begin{array}{l}\text { *ON-05 Repetitive information since } \\
\text { I often already know the } \\
\text { information from alternative } \\
\text { sources such as notifications. }\end{array}$ & $\begin{array}{l}\text { AFF-11 Adding gatekeepers that } \\
\text { validate access to functions of } \\
\text { third-party systems. }\end{array}$ & $\begin{array}{l}\text { AFF-03 Receiving aggregated } \\
\text { information from third-party } \\
\text { systems within channels. }\end{array}$ & $\begin{array}{l}\text { AFF-02 Receiving real-time } \\
\text { information from third-party } \\
\text { systems within channels. }\end{array}$ \\
\hline $\begin{array}{l}\text { CON-13 It is difficult to know how } \\
\text { to use them. }\end{array}$ & $\begin{array}{l}\text { CON-10 I can achieve the same } \\
\text { results with dedicated tools. }\end{array}$ & $\begin{array}{c}\text { AFF-09 Querying information from } \\
\text { third-party systems within } \\
\text { channels. }\end{array}$ & $\begin{array}{l}\text { AFF-08 Capturing data in } \\
\text { third-party systems from within } \\
\text { channels. }\end{array}$ & $\begin{array}{l}\text { AFF-05 Setting and getting } \\
\text { reminders within channels. }\end{array}$ \\
\hline \multirow[t]{5}{*}{$\begin{array}{l}\text { CON-03 Most of my work is not } \\
\text { digital. }\end{array}$} & $\begin{array}{l}\text { CON-02 My company constraints the } \\
\text { usage of such messengers. }\end{array}$ & $\begin{array}{c}\text { CON-04 They lead to information } \\
\text { overload. }\end{array}$ & $\begin{array}{c}\text { AFF-04 Receiving metrics and key } \\
\text { performance indicators from } \\
\text { third-party systems within } \\
\text { channels. }\end{array}$ & $\begin{array}{l}\text { AFF-06 Setting and getting nudges/ } \\
\text { triggers to action within channels. }\end{array}$ \\
\hline & $\begin{array}{l}\text { CON-07 The presented information } \\
\text { lacks graphical and visual } \\
\text { richness. }\end{array}$ & $\begin{array}{l}\text { CON-11 Lack of rich user interface } \\
\text { elements for entering data. }\end{array}$ & $\begin{array}{l}\text { AFF-10 Invoking functions from } \\
\text { third-party systems and make this } \\
\text { invocation visible within channels. }\end{array}$ & \\
\hline & $\begin{array}{l}\text { CON-14 It is more about playing and } \\
\text { having fun than real value added. }\end{array}$ & $\begin{array}{l}\text { AFF-13 Having messages processed } \\
\text { and replaced. }\end{array}$ & $\begin{array}{l}\text { AFF-14 Having messages processed } \\
\text { and visually enriched with user } \\
\text { interface elements. }\end{array}$ & \\
\hline & & $\begin{array}{l}\text { CON-12 Lack of configuration } \\
\text { possibilities without programming } \\
\text { customized integrations. }\end{array}$ & & \\
\hline & & $\begin{array}{l}\text { CON-09 Information is concealed } \\
\text { after I sent the message. }\end{array}$ & & \\
\hline
\end{tabular}

Fig. 11 Idealized Q-sort for viewpoint 2 - central information hub 


\begin{tabular}{|c|c|c|c|c|}
\hline-2 & -1 & 0 & 1 & 2 \\
\hline $\begin{array}{l}\text { CON-14 It is more about playing and } \\
\text { having fun than real value added. }\end{array}$ & $\begin{array}{l}\text { AFF- } 06 \text { Setting and getting nudges/ } \\
\text { triggers to action within channels. }\end{array}$ & $\begin{array}{l}\text { AFF-12 Having messages processed } \\
\text { and enriched with additional } \\
\text { information. }\end{array}$ & $\begin{array}{l}\text { CON-10 I can achieve the same } \\
\text { results with dedicated tools. }\end{array}$ & $\begin{array}{l}\text { AFF-02 Receiving real-time } \\
\text { information from third-party } \\
\text { systems within channels. }\end{array}$ \\
\hline $\begin{array}{l}\text { CON-03 Most of my work is not } \\
\text { digital. }\end{array}$ & $\begin{array}{l}\text { CON-12 Lack of configuration } \\
\text { possibilities without programming } \\
\text { customized integrations. }\end{array}$ & $\begin{array}{l}\text { AFF-05 Setting and getting } \\
\text { reminders within channels. }\end{array}$ & $\begin{array}{l}\text { CON-05 Repetitive information since } \\
\text { I often already know the } \\
\text { information from alternative } \\
\text { sources such as notifications. }\end{array}$ & $\begin{array}{c}\text { AFF-13 Having messages processed } \\
\text { and replaced. }\end{array}$ \\
\hline $\begin{array}{l}\text { AFF-10 Invoking functions from } \\
\text { third-party systems and make this } \\
\text { invocation visible within channels. }\end{array}$ & $\begin{array}{l}\text { CON-08 They introduce } \\
\text { process-orientation and reduce my } \\
\text { autonomy. }\end{array}$ & $\begin{array}{l}\text { AFF-08 Capturing data in } \\
\text { third-party systems from within } \\
\text { channels. }\end{array}$ & $\begin{array}{l}\text { AFF-03 Receiving aggregated } \\
\text { information from third-party } \\
\text { systems within channels. }\end{array}$ & $\begin{array}{l}\text { CON-09 Information is concealed } \\
\text { after I sent the message. }\end{array}$ \\
\hline \multirow[t]{5}{*}{$\begin{array}{l}\text { CON-02 My company constraints the } \\
\text { usage of such messengers. }\end{array}$} & $\begin{array}{c}\text { CON-04 They lead to information } \\
\text { overload. }\end{array}$ & $\begin{array}{c}\text { AFF-01 Receiving status } \\
\text { notifications and updates from } \\
\text { third-party systems within } \\
\text { channels. }\end{array}$ & $\begin{array}{c}\text { CON-06 Repetitive information since } \\
\text { I use these systems in my everyday } \\
\text { work. }\end{array}$ & $\begin{array}{l}\text { CON-13 It is difficult to know how } \\
\text { to use them. }\end{array}$ \\
\hline & $\begin{array}{l}\text { CON-01 Most software at work is not } \\
\text { open enough and has limited } \\
\text { integrations with messenger. }\end{array}$ & $\begin{array}{c}\text { AFF-07 Setting and getting nudges/ } \\
\text { triggers to action and } \\
\text { possibilities to resolve it within } \\
\text { the channel. }\end{array}$ & $\begin{array}{l}\text { AFF-14 Having messages processed } \\
\text { and visually enriched with user } \\
\text { interface elements. }\end{array}$ & \\
\hline & \multirow[t]{3}{*}{$\begin{array}{l}\text { AFF-11 Adding gatekeepers that } \\
\text { validate access to functions of } \\
\text { third-party systems. }\end{array}$} & $\begin{array}{l}\text { AFF-09 Querying information from } \\
\text { third-party systems within } \\
\text { channels. }\end{array}$ & $\begin{array}{l}\text { CON-11 Lack of rich user interface } \\
\text { elements for entering data. }\end{array}$ & \\
\hline & & $\begin{array}{l}\text { AFF-04 Receiving metrics and key } \\
\text { performance indicators from } \\
\text { third-party systems within } \\
\text { channels. }\end{array}$ & & \\
\hline & & $\begin{array}{l}\text { CON-07 The presented information } \\
\text { lacks graphical and visual } \\
\text { richness. }\end{array}$ & & \\
\hline
\end{tabular}

Fig. 12 Idealized Q-sort for viewpoint 3 - difficult to use black box \& worse than dedicated tools

group shares the perception that chatbots are valuable for receiving real-time information and as a means for having messages processed and replaced (e.g., through a Giphy integration): "Most things are easier in a dedicated tool, but the most important thing for integrations are notifications and message enhancements" (Participant 1).

\section{Viewpoint 4 - as shadow IT in a restrictive and closed legacy environment}

The forth viewpoint can be symbolically described as "driving with the handbrake on". Namely, it represents the perceptions of employees, which use enterprise messengers in (large)

\begin{tabular}{|c|c|c|c|c|}
\hline-2 & -1 & 0 & 1 & 2 \\
\hline $\begin{array}{l}\text { CON-03 Most of my work is not } \\
\text { digital. }\end{array}$ & $\begin{array}{l}\text { AFF-04 Receiving metrics and key } \\
\text { performance indicators from } \\
\text { third-party systems within } \\
\text { channels. }\end{array}$ & $\begin{array}{l}\text { AFF-06 Setting and getting nudges/ } \\
\text { triggers to action within channels. }\end{array}$ & $\begin{array}{c}\text { AFF-07 Setting and getting nudges/ } \\
\text { triggers to action and } \\
\text { possibilities to resolve it within } \\
\text { the channel. }\end{array}$ & $\begin{array}{l}\text { CON-02 My company constraints the } \\
\text { usage of such messengers. }\end{array}$ \\
\hline $\begin{array}{l}\text { AFF-01 Receiving status } \\
\text { notifications and updates from } \\
\text { third-party systems within } \\
\text { channels. }\end{array}$ & $\begin{array}{l}\text { AFF-05 Setting and getting } \\
\text { reminders within channels. }\end{array}$ & $\begin{array}{l}\text { CON-12 Lack of configuration } \\
\text { possibilities without programming } \\
\text { customized integrations. }\end{array}$ & $\begin{array}{l}\text { AFF-14 Having messages processed } \\
\text { and visually enriched with user } \\
\text { interface elements. }\end{array}$ & $\begin{array}{l}\text { AFF-13 Having messages processed } \\
\text { and replaced. }\end{array}$ \\
\hline $\begin{array}{l}\text { CON-13 It is difficult to know how } \\
\text { to use them. }\end{array}$ & $\begin{array}{l}\text { CON-11 Lack of rich user interface } \\
\text { elements for entering data. }\end{array}$ & $\begin{array}{l}\text { CON-09 Information is concealed } \\
\text { after I sent the message. }\end{array}$ & $\begin{array}{c}\text { AFF-09 Querying information from } \\
\text { third-party systems within } \\
\text { channels. }\end{array}$ & $\begin{array}{l}\text { AFF-12 Having messages processed } \\
\text { and enriched with additional } \\
\text { information. }\end{array}$ \\
\hline \multirow[t]{5}{*}{$\begin{array}{l}\text { CON-14 It is more about playing and } \\
\text { having fun than real value added. }\end{array}$} & $\begin{array}{c}\text { CON-08 They introduce } \\
\text { process-orientation and reduce my } \\
\text { autonomy. }\end{array}$ & $\begin{array}{l}\text { AFF-10 Invoking functions from } \\
\text { third-party systems and make this } \\
\text { invocation visible within channels. }\end{array}$ & $\begin{array}{l}\text { AFF-08 Capturing data in } \\
\text { third-party systems from within } \\
\text { channels. }\end{array}$ & $\begin{array}{l}\text { CON-01 Most software at work is not } \\
\text { open enough and has limited } \\
\text { integrations with messenger. }\end{array}$ \\
\hline & $\begin{array}{c}\text { CON-04 They lead to information } \\
\text { overload. }\end{array}$ & $\begin{array}{l}\text { AFF-03 Receiving aggregated } \\
\text { information from third-party } \\
\text { systems within channels. }\end{array}$ & $\begin{array}{c}\text { CON-05 Repetitive information since } \\
\text { I often already know the } \\
\text { information from alternative } \\
\text { sources such as notifications. }\end{array}$ & \\
\hline & \multirow[t]{3}{*}{$\begin{array}{c}\text { CON-07 The presented information } \\
\text { lacks graphical and visual } \\
\text { richness. }\end{array}$} & $\begin{array}{l}\text { AFF-11 Adding gatekeepers that } \\
\text { validate access to functions of } \\
\text { third-party systems. }\end{array}$ & $\begin{array}{l}\text { AFF-02 Receiving real-time } \\
\text { information from third-party } \\
\text { systems within channels. }\end{array}$ & \\
\hline & & $\begin{array}{c}\text { CON-06 Repetitive information since } \\
\text { I use these systems in my everyday } \\
\text { work. }\end{array}$ & & \\
\hline & & $\begin{array}{l}\text { CON-10 I can achieve the same } \\
\text { results with dedicated tools. }\end{array}$ & & \\
\hline
\end{tabular}

Fig. 13 Idealized Q-sort for viewpoint 4 - shadow IT in a restrictive and closed legacy environment 
companies that constraint the usage of such enterprise messengers. In addition, the perceptions are shaped by barriers that result from the available IT infrastructure with a portfolio of enterprise software that is not open enough and lacks integrations into these enterprise messengers. Participants that agree to CON-01 and CON-02 in their Q-Sort comment this viewpoint as follows: "The current legacy systems are not made for such cloud-based tools. Currently I'm working at a big insurance company where most of their systems do not work with Slack or a similar tools" (Participant 7). "Unfortunately, I cannot even connect our ticketing or CRM system to Slack or other messenger systems due to data security reasons. I can of course understand the reasoning behind this decision, but it would be possible to properly handle such integrations (with some more effort) to be compliant with obligations we have towards our customers" (Participant 4). Accordingly, the value of chatbots in such work environments is limited. "We use some closed software that would be neat to integrate to Slack, but which cannot be done. If it would be possible, the value of integrations would be higher" (Participant 26).

\section{Viewpoint 5 - as spammy and process-enforcing burden}

The fifth viewpoint represents a drawback from using chatbots to receive messages from third-party systems. This group of employees shares the feeling that such integrations lead to information overload: "I can't work when I'm bombarded by everything that is happening around me. Important messages are already conveyed through phone or in person. If there is a real issue, people will notice" (Participant 14). At the same time, employees point out the importance of a proper configuration of chatbots to keep employees engaged in team channels: "I hate getting automated messages as they end up in spamming the whole channels and no one reacts to updates anymore" (Participant 27). Further differences in viewpoints become apparent in how employees perceive the introduction of processorientation within social information systems. One standpoint is shaped by perceptions of employees that suffer from a reduced degree of autonomy, since chatbots are "another way for people to leave a paper trail which you have to follow" (Participant 14). This is heavily in contrast to other participants from other organizational settings: "At least in our company, all the integrations are complementary, and employees are not enforced to use it. The ones that see a benefit in it are using it, the other ones can do the same stuff with proprietary dedicated applications" (Participant 3). Lastly, participants explain that the perception of information overload depends on the job profile and employment type: "One issue is that part-time employees are not interested in getting the information about a certain project on the days they don't work for this project" (Participant 25).

\section{Discussion and implications}

Our results show higher-level affordances that emerge for members of group channels in which the identified 14

\begin{tabular}{|c|c|c|c|c|}
\hline-2 & -1 & 0 & 1 & 2 \\
\hline $\begin{array}{l}\text { AFF-02 Receiving real-time } \\
\text { information from third-party } \\
\text { systems within channels. }\end{array}$ & $\begin{array}{l}\text { CON-10 I can achieve the same } \\
\text { results with dedicated tools. }\end{array}$ & $\begin{array}{l}\text { CON-14 It is more about playing and } \\
\text { having fun than real value added. }\end{array}$ & $\begin{array}{l}\text { AFF-13 Having messages processed } \\
\text { and replaced. }\end{array}$ & $\begin{array}{l}\text { AFF-14 Having messages processed } \\
\text { and visually enriched with user } \\
\text { interface elements. }\end{array}$ \\
\hline $\begin{array}{l}\text { CON-13 It is difficult to know how } \\
\text { to use them. }\end{array}$ & $\begin{array}{c}\text { AFF-09 Querying information from } \\
\text { third-party systems within } \\
\text { channels. }\end{array}$ & $\begin{array}{c}\text { AFF-04 Receiving metrics and key } \\
\text { performance indicators from } \\
\text { third-party systems within } \\
\text { channels. }\end{array}$ & $\begin{array}{l}\text { AFF-05 Setting and getting } \\
\text { reminders within channels. }\end{array}$ & $\begin{array}{l}\text { AFF-03 Receiving aggregated } \\
\text { information from third-party } \\
\text { systems within channels. }\end{array}$ \\
\hline $\begin{array}{l}\text { **4 AFF-08 Capturing data in } \\
\text { third-party systems from within } \\
\text { channels. }\end{array}$ & $\begin{array}{l}\text { AFF-10 Invoking functions from } \\
\text { third-party systems and make this } \\
\text { invocation visible within channels. }\end{array}$ & $\begin{array}{l}\text { CON-12 Lack of configuration } \\
\text { possibilities without programming } \\
\text { customized integrations. }\end{array}$ & $\begin{array}{c}\text { AFF-07 Setting and getting nudges/ } \\
\text { triggers to action and } \\
\text { possibilities to resolve it within } \\
\text { the channel. }\end{array}$ & $\begin{array}{l}\text { CON-04 They lead to information } \\
\text { overload. }\end{array}$ \\
\hline \multirow[t]{5}{*}{$\begin{array}{l}\text { AFF-01 Receiving status } \\
\text { notifications and updates from } \\
\text { third-party systems within } \\
\text { channels. }\end{array}$} & $\begin{array}{l}\text { CON-03 Most of my work is not } \\
\text { digital. }\end{array}$ & $\begin{array}{l}\text { CON-11 Lack of rich user interface } \\
\text { elements for entering data. }\end{array}$ & $\begin{array}{l}\text { * CON-08 They introduce } \\
\text { process-orientation and reduce my } \\
\text { autonomy. }\end{array}$ & $\begin{array}{l}\text { AFF-06 Setting and getting nudges/ } \\
\text { triggers to action within channels. }\end{array}$ \\
\hline & $\begin{array}{l}\text { CON-01 Most software at work is not } \\
\text { open enough and has limited } \\
\text { integrations with messenger. }\end{array}$ & $\begin{array}{c}\text { CON-06 Repetitive information since } \\
\text { I use these systems in my everyday } \\
\text { work. }\end{array}$ & $\begin{array}{c}\text { CON-05 Repetitive information since } \\
\text { I often already know the } \\
\text { information from alternative } \\
\text { sources such as notifications. }\end{array}$ & \\
\hline & \multirow[t]{3}{*}{$\begin{array}{l}\text { CON-02 My company constraints the } \\
\text { usage of such messengers. }\end{array}$} & $\begin{array}{l}\text { CON-07 The presented information } \\
\text { lacks graphical and visual } \\
\text { richness. }\end{array}$ & $\begin{array}{l}\text { AFF-11 Adding gatekeepers that } \\
\text { validate access to functions of } \\
\text { third-party systems. }\end{array}$ & \\
\hline & & $\begin{array}{l}\text { CON-09 Information is concealed } \\
\text { after I sent the message. }\end{array}$ & & \\
\hline & & $\begin{array}{l}\text { AFF-12 Having messages processed } \\
\text { and enriched with additional } \\
\text { information. }\end{array}$ & & \\
\hline
\end{tabular}

Fig. 14 Idealized Q-sort for viewpoint 5 - spammy and process-enforcing burden 


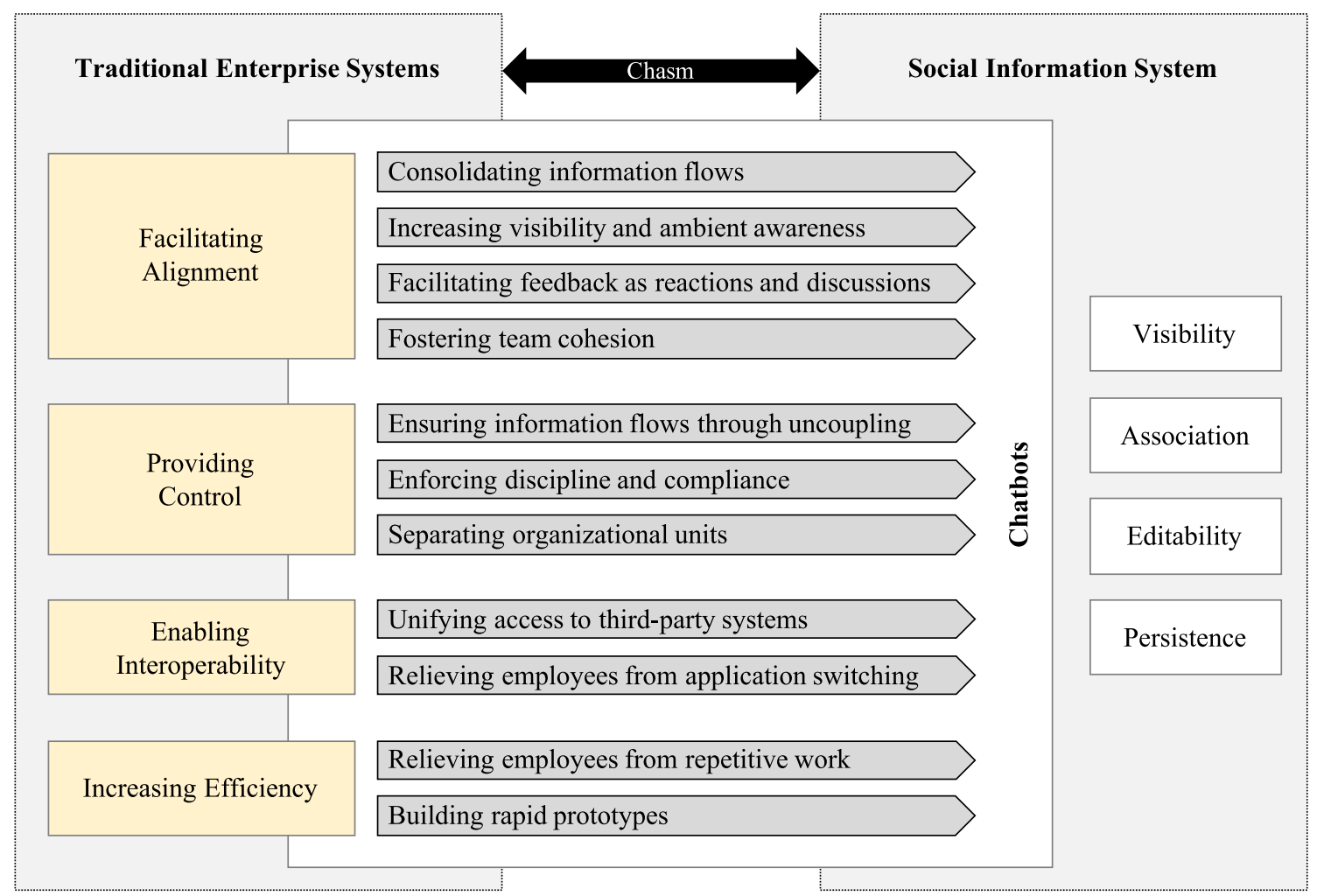

Affordances of traditional enterprise systems

(Mettler \& Winter, 2016)
Higher level affordances of chatbots within social information systems (Results of the research at hand)
Affordances of social information systems

(Treem \& Leonardi, 2012)

Fig. 15 Chatbots augment social information systems with affordances of traditional enterprise systems

lower-level affordances are actualized. Grounded in the emergence of higher-level affordances, we now discuss broader implications of our insights.

\section{Crossing the chasm: chatbots augment social information systems with affordances of traditional enterprise systems}

Figure 15 illustrates how the identified higher-level affordances of chatbots within enterprise messengers enable organizations (1) to facilitate alignment by integrating information (e.g., by receiving messages that consolidate information flows), (2) to provide control mechanisms (e.g., by getting and setting triggers that enforce discipline), (3) to enable interoperability (e.g., by querying and invoking functionality in order to unify access to third-party systems), and (4) to increase efficiency (e.g., by enriching messages to relieving employees from repetitive work).

In turn, these four dimensions (i.e., alignment, control, interoperability, efficiency) are well-known affordances of traditional enterprise systems (Mettler and Winter 2016). We therefore argue that chatbots augment social information systems of organizations (e.g., enterprise messengers such as Slack and Microsoft Teams) with affordances of traditional
Fig. 16 Development of slack apps and integrations from 2016 to 2018 (sorted by absolute growth)

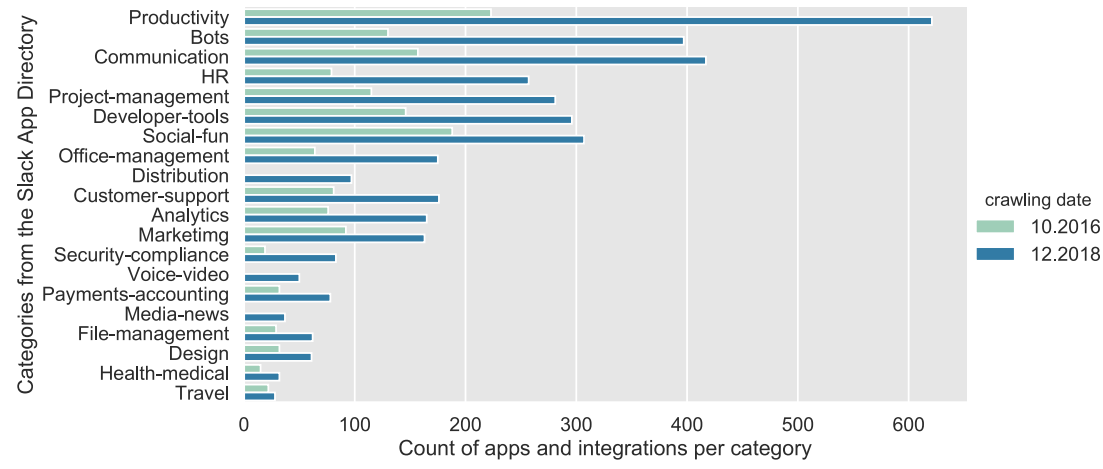


enterprise systems. This is achieved by enabling the linkage of social interactions within enterprise messengers with thirdparty systems and business processes. Hence, chatbots can be seen as valuable to cross the chasm between traditional enterprise systems and social information systems.

Triangulating this insight with our results from the preliminary study in which we crawled the full list of publicly available Slack Apps and Integrations enables a discussion of broader implications. Figure 16 shows the number of Slack Apps and Integrations (and their absolute growth) per category. In particular, the categories related to communication and coordination, human resources (HR), and project management have grown tremendously over the past two years, which may not only affect the corresponding enterprise systems, but also the corresponding research streams. However, this also applies to categories such as marketing, distribution and customer support, which doubled in the number of integrations with third-party enterprise systems.

\section{Implications for theory}

Augmenting social information systems with affordances of enterprise systems contrasts prior research that highlights traditional enterprise systems that are enhanced with social features. For example, social features are added to business process management (BPM) systems (Bruno et al. 2011; Schmidt and Nurcan 2009), business intelligence (BI) software (Alpar et al. 2015), enterprise resource planning (ERP) systems (Shankararaman and Kit Lum 2013), and inter-organizational systems such as supply chain management (SCM) software (Gonzalez 2013; Steinhueser et al. 2015). In contrast, our research puts social information systems at the focal point (e.g., Slack and Microsoft Teams) and explains how chatbots augment these social information systems with affordances of traditional enterprise systems. Therewith, we contribute a novel perspective on the integration and entanglement of social and enterprise systems that has four essential implications for theory.

First, crossing the chasm between social and traditional enterprise systems has broader implications that extend the discourse on paradoxical tensions (Ciriello et al. 2018b; Smith et al. 2017). Namely, we offer a novel perspective on how organizations may balance novel digital with traditional systems, flexibility and malleability with stability and control, exploration with exploitation, and agility with discipline approaches. More specifically, our results show how novel digital technologies can be combined with traditional enterprise systems (Seddon et al. 2010; Sedera and Lokuge 2017; Sedera et al. 2016). This is particularly relevant, since organizations are moving away from monolithic enterprise systems into portfolios of interlinked information systems and digital platforms, which provide them with an "ecosystem of providers and suppliers of tools, techniques, and practices, beyond the conventional boundaries of traditional corporate IT" (Harris et al. 2012; Sedera et al. 2016, p. 367; Yoo et al. 2012). Further, our results point out that enterprise messengers as social information systems are not limited to their well-known characteristics of flexibility and malleability (Richter and Riemer 2013; Schmitz et al. 2016). In fact, chatbots can help organizations in their digital and distributed innovation endeavors which demand for carefully balancing flexibility and malleability with stability and control (Ciriello et al. 2018a; Tilson et al. 2010; Yoo et al. 2012). In a broader perspective, this may enable organizations to balance their exploration (innovation) and exploitation (efficiency) activities, thus, to improve their organizational ambidexterity (Andriopoulos and Lewis 2009; March 1991; Tushman and O Reilly 1996). Finally, agile software development approaches are characterized by self-organizing and cross-functional teams that rely on rapid feedback and change to continuously design, improveme, and test software (Conboy 2009; McHugh et al. 2011; Tripp et al. 2016; Wang et al. 2012). However, a central challenge of agile teams is to find the right degree of formalization and coordination within project teams (Strode et al. 2012) and between self-managed teams (Ingvaldsen and Rolfsen 2012). In particular, research is needed on how to scale agility and balance agility with discipline and plan-driven approaches (Boehm and Turner 2003; Dingsøyr et al. 2018; Gerster et al. 2018). Our results show how agile teams adopt enterprise messengers in practice and reveal that for some employees chatbots act as a central hub to coordinate human and machine work (Viewpoint 2), while for others they become a process-enforcing burden (Viewpoint 5).

Second, our results have implications for research on distributed and virtual work. Namely, prior research on distributed (Cummings et al. 2009; Srikanth and Puranam 2011; Vlaar et al. 2008) and virtual work (Bailey et al. 2012; Griffith et al. 2003; Jarvenpaa and Leidner 1999; Maznevski and Chudoba 2000) emphasizes the growing relevance of digital technologies to overcome the challenge of spatial and temporal distances. Our results illustrate novel work practices that go beyond human-tohuman collaboration and include machine-to-human as well as human-to-machine collaboration. The identified affordances may contribute to impede the problems faced in distributed and virtual work. Namely, prior research suggests the separation of work in distributed teams impedes the ability of employees to communicate effectively (Meyer et al. 2015). Cramton (2001) distinguishes five types of mutual knowledge problem that distributed teams face: failure to communicate and retain contextual information, unevenly distributed information, difficulty communicating and understanding the salience of information, differences in speed of access to information, and difficulty interpreting the meaning of silence. Identified higher-level affordances such as 'consolidating information flows', 'increasing visibility and ambient awareness', 'facilitating feedback as reactions and discussions', 'ensuring information flows through uncoupling', and 'unifying access to third-party systems' suggest that chatbots may contribute to impede these problems. Furthermore, distributed teams are known to face trust issues 
(Jarvenpaa and Leidner 1999; Newell et al. 2007). The identified higher-level affordances such as 'increasing visibility and ambient awareness', 'facilitating feedback as reactions and discussions', and 'fostering team cohesion' suggest that chatbots may also contribute to impede trust issues in distributed teams.

Third, our results contribute to ongoing discourse on automation of work and the interplay between humans and machines (vom Brocke et al. 2018). We do this by pointing out higher-level affordances of chatbots that are characterized by their potentials for task automation (e.g., consolidating information flows, ensuring information flows through uncoupling, and relieving employees from repetitive work). Anchored in the principle of egalitarianism within social information systems, each member can add and use chatbots in the context of their conversational threads. As such, the principle of social production in social information systems goes beyond traditional user-generated content and includes the co-creation of automated information and workflows within shared conversational threads. Hence, we demonstrate how chatbots are a powerful instrument to enable organizational automation from bottom-up (rather than topdown). This is relevant, because automation is a key pillar of the current discourse on future work, which is increasingly performed by machines (vom Brocke et al. 2018). In this context, prior research has discussed how big data analytics technologies become generative digital technologies that enable service innovation (Lehrer et al. 2018), how hybrid intelligent decision support systems should be designed (Dellermann et al. 2018), and how the underlying logic of work is changing (Tumbas et al. 2018). In addition, we contribute a novel perspective on the interplay of people and machines that extends the ongoing discourse on hybrid arrangements of work. We do this by highlighting how social information systems (e.g., Slack and Microsoft Teams) are key organizational resources to enable bottom-up driven automation of communication, coordination and collaboration.

Fourth, our results have implications for performance feedback literature. Both academic literature (Levy et al. 2017; Schleicher et al. 2018) and practice-oriented literature (Armitage and Parrey 2013; Buckingham and Goodall 2015; Cappelli and Tavis 2016) emphasizes that traditional performance management lacks to be in line with current business cycles in providing timely feedback. The identified affordances reveal how chatbots (1) enable computer-generated feedback through automated information flows, and (2) facilitate computer-mediated feedback between employees through reactions and discussions. Given this use of chatbots to facilitate timely feedback, they can be seen as a complementary alternative to computer-mediated digital feedback systems such as dedicated feedback apps (Stoeckli et al. 2019). Therewith, our findings respond to calls for research to increase our understanding of informal day-to-day feedback and to investigate technology usage for performance management (Ashford and Cummings
1983; Levy et al. 2017; Schleicher et al. 2018). For example, the chatbot in organization Beta calculates velocity measures and posts the relative movement of each project to conversational threads (see Fig. 8). Also, the companies Epsilon, Eta and Theta harness chatbots to post analytics data, reviews and ratings from app stores to the corresponding project channels. These automated feedback flows described in the present research can be interpreted as computer-generated feedback that comes from the job (Hackman and Oldham 1976) rather than from other coworkers (Hackman and Lawler 1971). These findings are in line with literature that investigates chatbots dedicated to feedback exchange (Lechler et al. 2019). However, the implications of this research are much broader. Figure 16 highlights the diversity of integrations with numerous enterprise systems (e.g., software for distribution, customer support, marketing, accounting, and design), which may be used to assess the performance and generate feedback. As such, chatbots can be seen as feedback facilitating digital technologies that facilitate self-monitoring of teams (Hermsen et al. 2016). This, in turn, is particularly interesting in the light of agile practices that institutionalize feedback (McHugh et al. 2011; Tripp et al. 2016).

\section{Implications for practice}

Chatbots provide value potentials for organizations to improve internal workflows and collaboration through facilitating and enabling to harness enterprise systems affordances (i.e., facilitating alignment, providing control, enabling interoperability, and increasing efficiency) in the context of social information systems (e.g., Slack).

This has three key implications for practitioners in the light of an increasingly digital world that demands for distributed innovation. First of all, firms should leverage the social features of their (existing) social information systems to integrate their enterprise systems through chatbots rather than enrich each traditional enterprise system with social features. Second, our findings underline the relevance of opening up traditional enterprise systems through the conscious design of corresponding interfaces (e.g., API's) to allow bridging the world of traditional enterprise systems and social information systems. This in turn, allows to harness our identified affordances. Third, organizations should be aware that while traditional enterprise systems were usually top-down driven, social information systems are bottom-up driven. While chatbots do bridge this chasm, this may have positive and negative consequences. On the one hand, employees can harness chatbots for bottom-up driven automation. On the other hand, employees may integrate traditional enterprise without awareness of its consequences (e.g., introducing a chatbot that posts feedback in the form of metrics in group channels should be well thought-out, since it has severe consequences on job satisfaction and motivation). 


\section{Affordance-theoretical peculiarities of chatbots}

Interpreting the results through the affordance theory reveals further characteristics of chatbots in general.

\section{Affordance-related dependencies between individual actors} The perception of affordances depends on the available information (Bernhard et al. 2013). Markus and Silver (2008), for example, emphasize the symbolic expressions that are communicated by IT artifacts to a potential user to reveal meaning and potential uses. In this regard, chatbots have a major disadvantage, because their symbolic expressions are rare (especially for chatbots of Category 3 and Category 4). First, the information on available chatbots is hidden and has to be polled by the user through interaction with the chatbot. Second, for a given chatbot, our interviewees indicated struggles with recognizing the available possibilities for action. Interestingly, our results reveal affordances of chatbots with the characteristics that their actualization within a shared conversational thread leads to effects that are disclosed to other members of the channel. This either occurs 1) when the outcome of the actualization is posted into the shared conversational thread (e.g., creating video conference by invoking functionality and making invocation visible as described in Affordance 3.4), and 2) when the text entered by the actualizing user is disclosed in the conversational thread (e.g., "/poll 'Do you like this article so far?' 'Yes' 'No'). Therewith, the information about the availability of the actualized action potential becomes visible to others. From an affordance point of view, this indicates that the actualization of lower-level affordances by User 1 may lead to its perception by User 2 (see Fig. 17).

Emergence of individualized, collective, and shared affordances While technical users may develop and install custom chatbots, most users may simply install publicly available chatbots (e.g., from the Slack App Directory). However, in both cases, adding a chatbot to a conversational thread leads to the emergence of new affordances for the other members of this channel. The channel in which a chatbot is added to and in which the corresponding affordances are eventually actualized is socially determined by the actualizing user. Thus, the same IT artifact

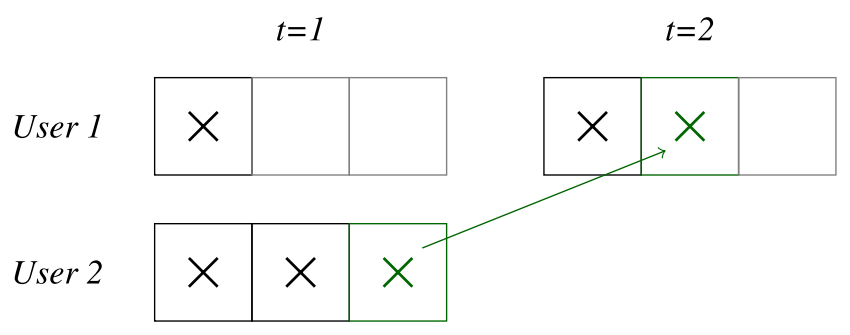

[emergence / perception / actualization]

Fig. 17 The actualization of an affordance by one user may facilitate its perception by another user can be put into different social contexts by the appropriating user and, thus, different kinds of affordances may emerge, e.g., individualized, collective or shared affordances (Paul M Leonardi 2013) as well as constraints. For example, a chatbot to capture a Trello task within Slack (Affordance 3.1) may be used individually, thus, leading to an individualized affordance. However, a user may put the same chatbot to a shared conversational thread. Shared affordances describe the similar use of the features of an IT artifact by all considered actors (Paul M Leonardi 2013) and emerge "as soon as several individuals know a function" (Balci et al. 2014, p. 8). Collective affordances are collectively created by all actors of a group allowing the group to achieve something, which otherwise would not be possible (Balci et al. 2014; Paul M Leonardi 2013). As such, the characteristic described above (i.e., visibility of the actualization by one user for other users) can be seen to facilitate shared as well as collective affordances. However, our results show how these higher-level affordances may not only be enabling, but also constraining, e.g., if members of a shared conversational thread do not share the same goals. This is where we see the biggest value and likewise the biggest challenge arising from chatbots that are integrated in shared conversational threads (e.g., by facilitating reactions, discussions, ambient awareness).

High actualization effort Prior research suggests that the actualization and, accordingly, the realization of effects, is influenced by the actualization effort and the expected outcome (Bernhard et al. 2013). In our research, the perceived expected outcome depends on how other members of the channel act. In fact, our results reveal constraints, such as information overload. At the same time, the perceived expected outcome can also change over time. Affordances have to be seen in the context of the alternatives, because employees constantly compare affordances (Glowalla et al. 2014). Thus, our results indicate, that the actualization effort has to be in balance with the perceived expected outcome to facilitate the actualization of the respective affordances and thus the successful use of the IT artifact.

\section{Implications for theory}

Through backing our research endeavor with the affordance theory, we contribute three important theoretical implications to the extant body of knowledge. First, though several authors focus on the interrelationship of affordances (e.g., through an affordances dependency diagram (Strong et al. 2014)), it remains unclear how the actualization of affordances affects the context-specific perception of affordances and constraints of other users (Bloomfield et al. 2010; Strong et al. 2014). Against this backdrop, our research illuminates how the actualization of one user may facilitate the emergence and the consecutive perception by another user. In contrast, prior research has shown dependencies between individual affordances (Glowalla et al. 2014) and dependencies between different unit 
of analyses, e.g., individual and organizational affordances (Strong et al. 2014). Second, drawing on the concept of individualized, shared, and collective affordances of Leonardi (2013), we detail how the use of chatbots in diverse social contexts may lead to the emergence of either individualized, shared, and collective affordances through affecting the technoorganizational context. Third, following the thinking of Bygstad et al. (2016) the manipulation of the techno-organization context (i.e., entangled networks of human, social and technical objects) through the actualization of affordances is supposed to affect not only the emergence, perception, and actualization of affordances but also the emergence of constraints. Through eliciting the constraints of the use of chatbots, we contribute empirical insights on how the actualization of an affordance affects the technoorganizational context and, in turn, the emergence, perception, and actualization of affordances.

\section{Implications for practice}

These findings have implications for organizations that design instance messengers and chatbots as well as for organizations that use chatbots. First, designers of instant messengers need to acknowledge that, given a particular chatbot, members of group channels perceive different higher-level affordances and constraints (see Fig. 8 within results). Our results suggest that offering options to individually mute channels does not solve this issue, because the perceived constraints (e.g., message postings leading to information overflow) are not in line with the perceived relevance of human conversations in group channels (e.g., muting its team channel may not be an option for its manager, however, a chatbot that floods the corresponding channel with operational details may be perceived as constraining). Furthermore, providing chatbot developers with graphical user interface elements may help to reduce the relatively high actualization effort. Second, designers of chatbots should consider the affordance-related dependencies between individual users to counter the disadvantage of rare symbolic expressions (while preventing information overflow). Specifically, we have shown that the visibility of the actualization of an affordance by one user may lead to its perception by other users (and hence, may foster adoption), or also to the emergence of constraints such as information overflow. Furthermore, designers of chatbots should try to foster affordance actualization by reducing the relatively high actualization effort through the exploitation of graphical user interface elements (e.g., reducing effort for data input through buttons). Third, the three discussed affordance-theoretical peculiarities of chatbots need to be considered by organizations that use chatbots. In particular, the social context in which chatbots are introduced (i.e., the group channel) influence to a large extend what higher-level affordances and constraints emerge. Before introducing chatbots, employees should consciously consider their set of group channels and the corresponding needs of group members.

\section{Conclusion and future research}

In summary, we shed light on the previously unexplored and novel phenomenon of chatbots in the context of enterprise messengers by pointing out 14 lower-level affordances and constraints along four categories: receiving messages, getting and setting triggers, executing queries and invocations, and enriching messages. Our results further reveal patterns in the form of similarities and differences in how employees weigh the perception of these identified affordances against the perception of constraints. Perceptional similarities include that employees perceive affordances related to receiving messages from third-party systems as higher compared to all affordances and that the relevance of chatbots is assessed as highest in group channels that are related to projects at work. Perceptional differences among employees are highlighted along five different factors that show that chatbots within enterprise messengers are viewed (1) as operational assistants, (2) as central information hubs, (3) as difficult to use black boxes and worse alternatives to dedicated tools, (4) as shadow IT in restrictive and closed legacy environments, and (5) as spammy and process-enforcing burden. Emergent from the actualization journeys of the lower-level affordances and constraints, we elaborate higher level affordances, such as consolidating communication (e.g., have messages from multiple people and third-party systems in a chronologic thread) and automating information and work flows (e.g., ensure discipline, relieve employees, shorten feedback cycles).

We contribute to the body of social information systems by elucidating how chatbots augment social information systems with the affordances of traditional enterprise systems proposed by Mettler and Winter (2016). In a broader perspective of paradoxical tensions, we contribute a novel perspective on how to balance novel digital with traditional systems, flexibility and malleability with stability and control, exploration with exploitation, and agility with discipline. Further, we contribute to the body of affordance literature by discussing affordancetheoretical peculiarities of chatbots, e.g., how the actualization of an affordance by one user may affect the affordance perception of other users (Fig. 8). At last, the paper at hand informs practitioners about affordances as well as constraints of enterprise messengers such as Slack and Microsoft Teams as well as by discussing implications for practice within the dedicated sections.

Nevertheless, our findings are subject to limitations. Due to the qualitative and interpretive research design, exhaustiveness cannot be guaranteed, and we cannot provide a verified theory. Therefore, future quantitative studies can further enrich our results in drawing on them and critically reflecting and verifying them. While our research considered multiple enterprise 
messengers, the focus was on one tool, that is Slack, within different organizational contexts. This may lead to biases in the identified affordances and constraints. On the one hand, other tools may simply have different material properties leading to the emergence of different affordances and constraints. On the other hand, the selection of the tool may influence the sample of users in that they have special characteristics. Finally, our interviewees were mainly based in Germany and Switzerland, which might affect our research findings. As counter measure, we conducted a preliminary analysis of the Slack directory, and triangulated our findings with material provided by our interviews. Anchored in the split of the Glaserian school (Glaser 1992) from the Straussian school of grounded theory (Corbin and Strauss 1990; Strauss and Corbin 1990), the following question arises: "At what point does the researcher's intervention or techniques force, instead of allow for, emergence?" (Walker and Myrick 2006, p. 553). By following Strauss and Corbin (1990), we strived to "never impose anything on the data" (p. 94) and, at the same time, applying their principle of theoretical sensitivity that encourages the use of analytic tools such as the affordance theory in order to allow for emergence of insights. Still, the use of analytical tools such as existing theory goes along with the risk to force the data in preconceived ways, thus, potentially leading to confirmation-bias.

We see four avenues for future research. First, we acknowledge the fruitful avenue for design-oriented research in the context of chatbots. Our research illuminating the affordances emergence of chatbots in the enterprise context as well as the discussed affordance-related peculiarities could be used as a starting point for eliciting and developing design propositions and a design theory for chatbots. In particular, it would be interesting how design decisions for chatbots have to be depended on the techno-organizational context to reduce the effort needed to actualize the affordances of chatbots and how these propositions need to take contextual conditions into account under which constraints emerge from chatbots in shared conversational threads.

Second, as enterprise messengers such as Slack become available for a broader audience of users (aside from software developers), future research can investigate how chatbots can be used to assess the work conducted by employees and to provide timely automated feedback. Furthermore, prior research has shown that the visibility and transparency on the progress of tasks (e.g., through agile practices such as daily stand-ups) have self-motivating effects (McHugh et al. 2011). Future research should clarify if this applies as well to feedback provided by chatbots (e.g., the chatbots in Fig. 5 discloses velocity metrics).

Third, as we selected Slack as representative enterprise messenger platform, future research is needed to confirm and extend our research findings using additional platforms (e.g., Microsoft Teams) and organizational contexts. Specifically, different quantitative approaches can be adopted for verification.

Fourth, future research should investigate further domainspecific enterprise systems that benefit from an integration in social information systems. For example, research on product development is emphasizing the increasing need for collaboration, knowledge exchange and communication within and across geographically distributed teams and suggests that social software applications can support tasks across various phases of the new product development process (Bertoni and Chirumalla 2011; Ming et al. 2008; Roch and Mosconi 2016; Rohmann et al. 2014). Chatbots may be harnessed to integrate domain-specific enterprise systems, e.g., Computer Aided Design (CAD) systems and Product Lifecycle Management (PLM) systems into social information systems.

\section{Appendix. Heatmaps of Cards Sorting Values from Phase 2 and Phase 3}

Fig. 18 Results of physical card sorting from phase 2

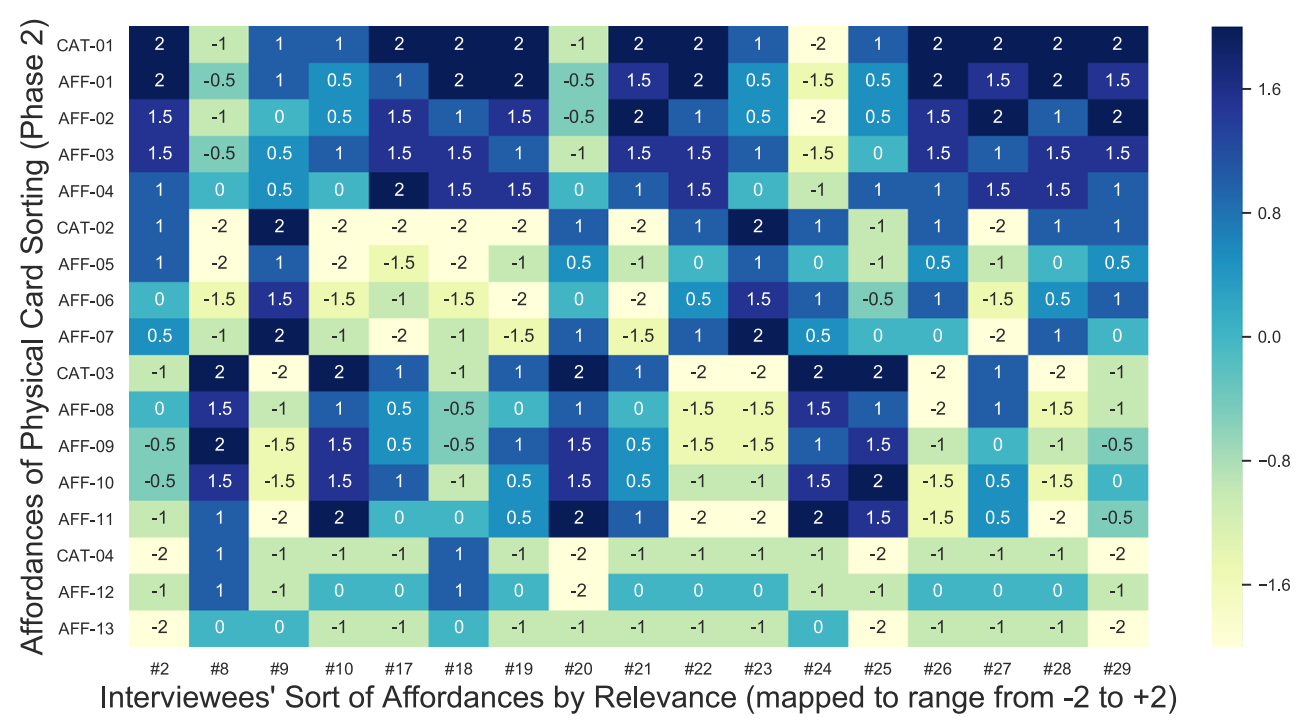


Fig. 19 Results of Q-sort from phase 3

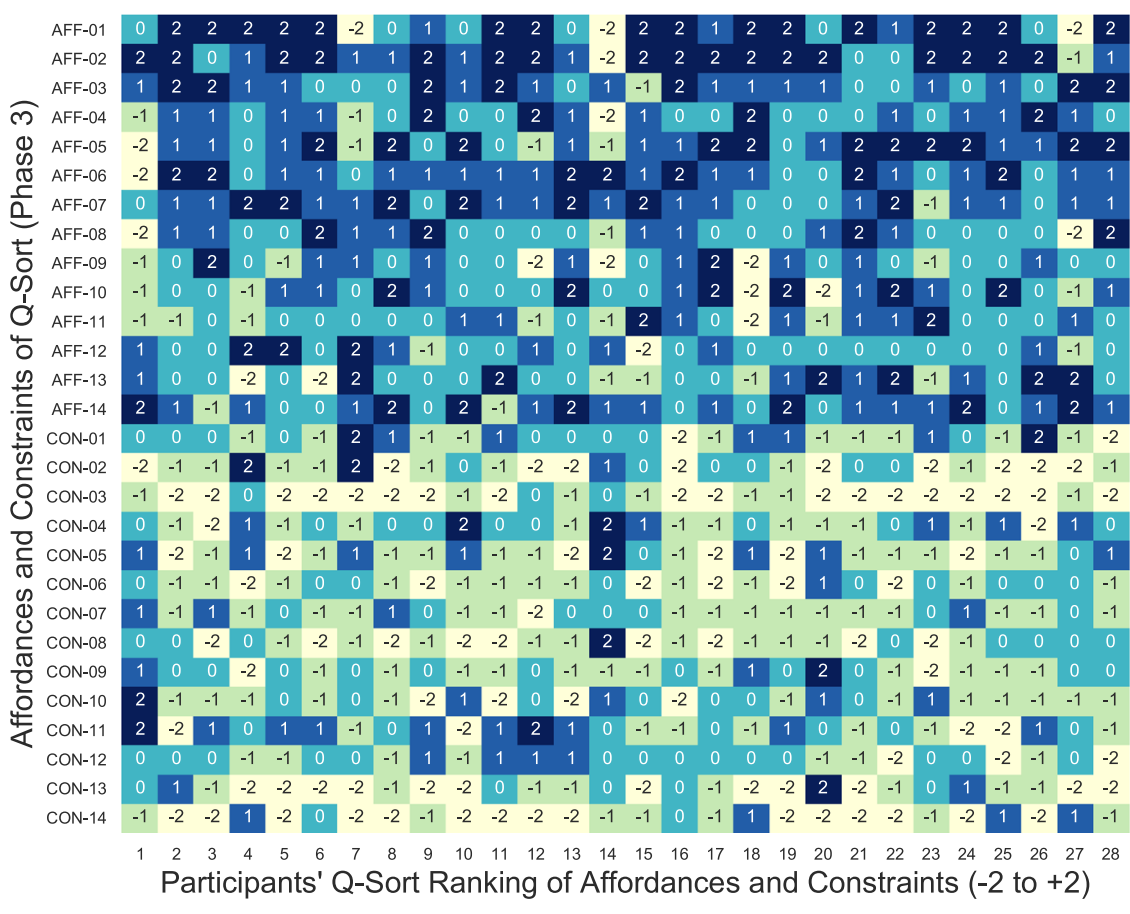

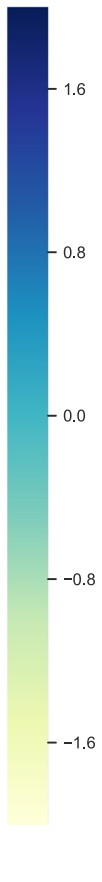

Open Access This article is distributed under the terms of the Creative Commons Attribution 4.0 International License (http:// creativecommons.org/licenses/by/4.0/), which permits unrestricted use, distribution, and reproduction in any medium, provided you give appropriate credit to the original author(s) and the source, provide a link to the Creative Commons license, and indicate if changes were made.

\section{References}

Alpar, P., Engler, T. H., \& Schulz, M. (2015). Influence of social software features on the reuse of business intelligence reports. Information Processing \& Management, 51(3), 235-251. https://doi.org/10. 1016/j.ipm.2015.01.004.

André, E. (2008). Design and evaluation of embodied conversational agents for educational and advisory software. Handbook of Conversation Design for Instructional Applications, 343-362.

Andriopoulos, C., \& Lewis, M. W. (2009). Exploitation-exploration tensions and organizational ambidexterity: Managing paradoxes of innovation. Organization Science, 20(4), 696-717. https://doi.org/10. 1287/orsc. 1080.0406 .

Armitage, A., \& Parrey, D. (2013). Reinventing performance management: Creating purpose-driven practices. People \& Strategy, 36(2), 26-33.

Ashford, S. J., \& Cummings, L. L. (1983). Feedback as an individual resource: Personal strategies of creating information. Organizational Behavior and Human Performance, 32(3), 370-398. https://doi.org/ 10.1016/0030-5073(83)90156-3.

Bailey, D. E., Leonardi, P. M., \& Barley, S. R. (2012). The lure of the virtual. Organization Science, 23(5), 1485-1504.

Baker, R., Thompson, C., \& Mannion, R. (2006). Q methodology in health economics. Journal of Health Services Research \& Policy, 11(1), 38-45. https://doi.org/10.1258/135581906775094217.

Baker, R., Wildman, J., Mason, H., \& Donaldson, C. (2014). Q-ing for health-a new approach to eliciting the public's views on health care resource allocation. Health Economics, 23(3), 283-297. https://doi. org/10.1002/hec.2914.

Balci, B., Rosenkranz, C., \& Schuhen, S. (2014). Identification of different affordances of information technology systems: An empirical study. ECIS 2014 Proceedings.

Banasick, S. (2019). KADE: A desktop application for Q methodology. Journal of Open Source Software, 4(36), 1360. https://doi.org/10. 21105/joss.01360.

Benbasat, I., \& Zmud, R. W. (2003). The identity crisis within the is discipline: Defining and communicating the discipline's core properties. MIS Quarterly, 27(2), 183-194.

Benkler, Y. (2006). The wealth of networks: how social production transforms markets and freedom. Yale University Press, New Haven.

Bernhard, E., Recker, J. C., \& Burton-Jones, A. (2013). Understanding the actualization of affordances: A study in the process modeling context. ICIS 2013 Proceedings.

Bertoni, M., \& Chirumalla, K. (2011). Leveraging Web 2.0 in new product development: Lessons learned from a cross-company study. Journal of Universal Computer Science, 17(4): 548-564.

Bloomfield, B. P., Latham, Y., \& Vurdubakis, T. (2010). Bodies, technologies and action possibilities: When is an affordance? Sociology, 44(3), 415-433. https://doi.org/10.1177/0038038510362469.

Boehm, B., \& Turner, R. (2003). Balancing agility and discipline: A guide for the perplexed. Portable Documents: Addison-Wesley Professional.

Brouwer, M. (1999). Q is accounting for tastes. Journal of Advertising Research, 39(2), 35-35.

Brown, S. R. (1980). Political subjectivity: Applications of $Q$ methodology in political science. Yale University Press.

Brown, S. R. (1993). A primer on Q methodology. 26.

Bruno, G., Dengler, F., Jennings, B., Khalaf, R., Nurcan, S., Prilla, M., ... Silva, R. (2011). Key challenges for enabling agile BPM with social software. Journal of Software Maintenance and Evolution: Research and Practice, 23(4): 297-326. https://doi.org/10.1002/ smr.523.

Buckingham, M., \& Goodall, A. (2015). Reinventing performance management. Harvard Business Review, 93(4), 40-50. 
Budiu, R. (2018). The user experience of chatbots. Retrieved December 13, 2018, from https://www.nngroup.com/articles/chatbots/.

Bygstad, B., Munkvold, B. E., \& Volkoff, O. (2016). Identifying generative mechanisms through affordances: A framework for critical realist data analysis. Journal of Information Technology, 31(1), 83-96. https://doi.org/10.1057/jit.2015.13.

Cappelli, P., \& Tavis, A. (2016). The performance management revolution. Harvard Business Review, 94(10), 58-67.

Ciriello, R. F., Richter, A., \& Schwabe, G. (2018a). Digital Innovation. Business \& Information Systems Engineering, 60, 1-7. https://doi. org/10.1007/s12599-018-0559-8.

Ciriello, R. F., Richter, A., \& Schwabe, G. (2018b). The paradoxical effects of digital artefacts on innovation practices. European Journal of Information Systems, 28(2), 1-24. https://doi.org/10. 1080/0960085X.2018.1524418.

Conboy, K. (2009). Agility from first principles: Reconstructing the concept of agility in information systems development. Information Systems Research, 20(3), 329-354. https://doi.org/10.1287/isre. 1090.0236

Coogan, J., \& Herrington, N. (2011). Q methodology: An overview. Research in Secondary Teacher Education, 1(2), 24-28.

Corbin, J. M., \& Strauss, A. (1990). Grounded theory research: Procedures, canons, and evaluative criteria. Qualitative Sociology, 13(1), 3-21. https://doi.org/10.1007/BF00988593.

Cowell, A. J., \& Stanney, K. M. (2005). Manipulation of non-verbal interaction style and demographic embodiment to increase anthropomorphic computer character credibility. International Journal of Human-Computer Studies, 62(2), 281-306. https://doi.org/10.1016/ j.ijhcs.2004.11.008.

Cramton, C. D. (2001). The mutual knowledge problem and its consequences for dispersed collaboration. Organization Science, 12(3), 346-371. https://doi.org/10.1287/orsc.12.3.346.10098.

Crutzen, R., Peters, G.-J. Y., Portugal, S. D., Fisser, E. M., \& Grolleman, J. J. (2011). An artificially intelligent chat agent that answers adolescents' questions related to sex, drugs, and alcohol: An exploratory study. The Journal of Adolescent Health, 48(5), 514-519. https:// doi.org/10.1016/j.jadohealth.2010.09.002.

Cummings, J. N., Espinosa, J. A., \& Pickering, C. K. (2009). Crossing spatial and temporal boundaries in globally distributed projects: A relational model of coordination delay. Information Systems Research, 20(3), 420-439. https://doi.org/10.1287/isre.1090.0239.

Dale, R. (2016). The return of the chatbots. Natural Language Engineering, 22(5), 811-817.

Davies, B. B., \& Hodge, I. D. (2007). Exploring environmental perspectives in lowland agriculture: A Q methodology study in East Anglia, UK. Ecological Economics: The Journal of the International Society for Ecological Economics, 61(2), 323-333. https://doi.org/ 10.1016/j.ecolecon.2006.03.002.

Dellermann, D., Lipusch, N., Ebel, P., \& Leimeister, J. M. (2018). Design principles for a hybrid intelligence decision support system for business model validation. Electronic Markets. https://doi.org/10.1007/ s12525-018-0309-2.

Demetis, D., \& Lee, A. S. (2018). When humans using the IT artifact becomes IT using the human artifact. Journal of the Association for Information Systems, 19(10), 5.

Dingsøyr, T., Moe, N. B., Fægri, T. E., \& Seim, E. A. (2018). Exploring software development at the very large-scale: A revelatory case study and research agenda for agile method adaptation. Empirical Software Engineering, 23(1), 490-520. https://doi.org/10.1007/ s10664-017-9524-2.

Donner, J. C. (2001). Using Q-sorts in participatory processes: An introduction to the methodology. Social Development Papers, 36, 24-49.

Dremel, C., Herterich, M. M., Wulf, J., \& vom Brocke, J. (2018). Actualizing big data analytics affordances: A revelatory case study. Information Management. https://doi.org/10.1016/j.im.2018.10.007.
Durward, D., Blohm, I., \& Leimeister, J. M. (2016). Crowd work. Business \& Information Systems Engineering, 58(4), 281-286. https://doi.org/10.1007/s12599-016-0438-0.

Dziopa, F., \& Ahern, K. (2011). A systematic literature review of the applications of Q-technique and its methodology. Methodology, 7(2), 39-55. https://doi.org/10.1027/1614-2241/a000021.

Eaton, B., Elaluf-Calderwood, S., Sorensen, C., \& Yoo, Y. (2015). Distributed tuning of boundary resources: The case of Apple's iOS service system. MIS Quarterly, 39(1), 217-243.

Faraj, S., \& Azad, B. (2012). The materiality of technology: An affordance perspective. In P M Leonardi, B. A. Nardi, \& J. Kallinikos (Eds.), Materiality and organizing: Social interaction in a technological world (pp. 237-258). Oxford: Oxford University Press.

Faulkner, P., \& Runde, J. (2010). The social, the material, and the ontology of non-material technological objects. Working Paper. Retrieved March 22, 2018, from https://pdfs.semanticscholar.org/ 003b/e307e113faefcd74db9347cee6d4d3751a12.pdf

Fincher, S., \& Tenenberg, J. (2005). Making sense of card sorting data. Expert Systems, 22(3), 89-93. https://doi.org/10.1111/j.1468-0394. 2005.00299.x.

Floridi, L., Taddeo, M., \& Turilli, M. (2009). Turing's imitation game: Still an impossible challenge for all machines and some judges _ - an evaluation of the 2008 Loebner contest. Minds Mach, 19(1), 145-150.

Fogg, B. J. (2002). Persuasive technology: Using computers to change what we think and do. Ubiquity, 2002(December). https://doi.org/ 10.1145/764008.763957.

Gerster, D., Dremel, C., \& Kelker, P. (2018). Scaling agility: How enterprises adopt agile forms of organizational design. ICIS 2018 Proceedings.

Ghazawneh, A., \& Henfridsson, O. (2013). Balancing platform control and external contribution in third-party development: The boundary resources model. Information Systems Journal, 23(2), 173-192.

Gianvecchio, S., Xie, M., Wu, Z., \& Wang, H. (2011). Humans and bots in internet chat: Measurement, analysis, and automated classification. IEEE/ACM Transactions on Networking, 19(5), 1557-1571. https://doi.org/10.1109/TNET.2011.2126591.

Gibson, J. J. (1977). The theory of affordances. In and Bransford Shaw, Robert (Ed.), Perceiving, acting and knowing (pp. 67-82). Lawrence Erlbaum Associates.

Glaser, B. G. (1992). Basics of grounded theory analysis: Emergence vs forcing. Sociology press.

Glowalla, P., Rosenkranz, C., \& Sunyaev, A. (2014). Evolution of IT use: A case of business intelligence system transition. ICIS 2014 Proceedings.

Gnewuch, U., Morana, S., \& Maedche, A. (2017). Towards designing cooperative and social conversational agents for customer service. ICIS 2017 Proceedings.

Gonzalez, A. (2013). The social side of supply chain management. Supply Chain Management Review, 17(4), 16-21.

Grand View Research. (2017). Size of the chatbot market worldwide in 2016 and 2025 (in million U.S. dollars). Retrieved December 13, 2018, from Statista website: https://www.statista.com/statistics/ 656596/worldwide-chatbot-market/

Granovetter, M. S. (1973). The strength of weak ties. The American Journal of Sociology, 78(6), 1360-1380.

Griffith, T. L., Sawyer, J. E., \& Neale, M. A. (2003). Virtualness and knowledge in teams: Managing the love triangle of organizations, individuals, and information technology. MIS Quarterly, 27(2), 265-287. https://doi.org/10.2307/30036531.

Hackman, J. R., \& Lawler, E. E. (1971). Employee reactions to job characteristics. The Journal of Applied Psychology, 55(3), 259286. https://doi.org/10.1037/h0031152.

Hackman, J. R., \& Oldham, G. R. (1976). Motivation through the design of work: Test of a theory. Organizational Behavior and Human 
Performance, 16(2), 250-279. https://doi.org/10.1016/00305073(76)90016-7.

Halaweh, M. (2012). Integration of grounded theory and case study: An exemplary application from e-commerce security perception research. JITTA: Journal of Information Technology Theory and Application, 13(1), 31.

Harris, J., Ives, B., \& Junglas, I. (2012). IT consumerization: When gadgets turn into enterprise IT tools. MIS Quarterly Executive, 11(3), 99-112.

Hermsen, S., Frost, J., Renes, R. J., \& Kerkhof, P. (2016). Using feedback through digital technology to disrupt and change habitual behavior: A critical review of current literature. Computers in Human Behavior, 57, 61-74. https://doi.org/10.1016/j.chb.2015.12.023.

Holzwarth, M., Janiszewski, C., \& Neumann, M. M. (2006). The influence of avatars on online consumer shopping behavior. Journal of Marketing, 70(4), 19-36. https://doi.org/10.1509/jmkg.70.4.19.

Hubbard, M., \& Bailey, M. J. (2018). Mastering microsoft teams: End user guide to practical usage, collaboration, and governance. https://doi.org/10.1007/978-1-4842-3670-3.

Ingvaldsen, J. A., \& Rolfsen, M. (2012). Autonomous work groups and the challenge of inter-group coordination. Human Relations; Studies Towards the Integration of the Social Sciences, 65(7), 861-881. https://doi.org/10.1177/0018726712448203.

Io, H. N., \& Lee, C. B. (2017, December). Chatbots and conversational agents: A bibliometric analysis. 215-219. https://doi.org/10.1109/ IEEM.2017.8289883.

Jarvenpaa, S. L., \& Leidner, D. E. (1999). Communication and Trust in global virtual teams. Organization Science, 10(6), 791-815. https:// doi.org/10.1287/orsc. 10.6.791.

Jung, D., Dorner, V., Weinhardt, C., \& Pusmaz, H. (2017). Designing a robo-advisor for risk-averse, low-budget consumers. Electronic Markets, 28, 1-14. https://doi.org/10.1007/s12525-017-0279-9.

Jung, D., Dorner, V., Glaser, F., \& Morana, S. (2018a). Robo-advisory digitalization and automation of financial advisory. Business \& Information Systems Engineering, 60(1), 81-86.

Jung, D., Erdfelder, E., \& Glaser, F. (2018b). Nudged to win: Designing robo-advisory to overcome decision inertia. Proceedings of the 26th European Conference on Information Systems (ECIS 2018). Presented at the Portsmouth, UK. Portsmouth, UK.

Kaplan, A. M., \& Haenlein, M. (2010). Users of the world, unite! The challenges and opportunities of social media. Business Horizons, 53(1), 59-68. https://doi.org/10.1016/j.bushor.2009.09.003.

Kerly, A., Hall, P., \& Bull, S. (2007). Bringing chatbots into education: Towards natural language negotiation of open learner models. Knowledge-Based Systems, 20(2), 177-185.

Kim, H., Ruiz, M. E., \& Peterson, L. (2007). Usability and effectiveness evaluation of a course-advising chat bot. Proceedings of the American Society for Information Science and Technology, 44(1), $1-5$.

Kim, W., Jeong, O.-R., \& Lee, S.-W. (2010). On social web sites. Information Systems, 35(2), 215-236. https://doi.org/10.1016/j.is. 2009.08.003.

Klaus, T., Wingreen, S. C., \& Blanton, J. E. (2010). Resistant groups in enterprise system implementations: A Q-methodology examination. Journal of Information Technology, 25(1), 91-106. https://doi.org/ 10.1057/jit.2009.7.

Klein, H. K., \& Myers, M. D. (1999). A set of principles for conducting and evaluating interpretive field studies in information systems. MIS Quarterly, 23(1), 67-93. https://doi.org/10.2307/249410.

Knight, W. (2016). Conversational Interfaces. MIT Technol. Rev., 119(2), $42-45$.

Koch, M. (2008). CSCW and enterprise 2.0-towards an integrated perspective. BLED 2008 Proceedings.

Krempels, K.-H., Spaniol, O., Scholz, T., Timm, I. J., \& Herzog, O. (2006). Interaction design. In S. Kirn, O. Herzog, P. Lockemann, \& O. Spaniol (Eds.), Multiagent Engineering: Theory and
Applications in Enterprises (pp. 383-403). https://doi.org/10.1007/ 3-540-32062-8 20.

Lasek, M., \& Jessa, S. (2013). Chatbots for customer service on hotels' websites. Information Systems in Management, 2(2), 146-158.

Lebeuf, C., Storey, M. A., \& Zagalsky, A. (2018). Software bots. IEEE Software, 35(1), 18-23.

Lechler, R., Stoeckli, E., Rietsche, R., \& Uebernickel, F. (2019). Looking beneath the tip of the iceberg: The two-sided nature of Chatbots and their roles for digital feedback exchange. ECIS 2019 Proceedings.

Lehrer, C., Wieneke, A., vom Brocke, J., Jung, R., \& Seidel, S. (2018). How big data analytics enables service innovation: Materiality, affordance, and the individualization of service. Journal of Management Information Systems, 35(2), 424-460. https://doi.org/ 10.1080/07421222.2018.1451953.

Leonardi, P. M. (2012). Materiality, sociomateriality, and socio-technical systems: What do these terms mean? How are they related? Do we need them? (p. 25). Materiality and Organizing: Social Interaction in a Technological World. https://doi.org/10.2139/ssrn.2129878.

Leonardi, P. M. (2013). When does technology use enable network change in organizations? A comparative study of feature use and shared affordances. MIS Quarterly, 37(3), 749-775.

Levy, H. P. (2016, October 18). Gartner predicts a virtual world of exponential change - smarter with Gartner. Retrieved March 22, 2018 , from https://www.gartner.com/smarterwithgartner/gartner-predictsa-virtual-world-of-exponential-change/

Levy, P. E., Tseng, S. T., Rosen, C. C., \& Lueke, S. B. (2017). Performance management: A marriage between practice and science-just say "I do." In Research in Personnel and Human Resources Management (Vol. 35, pp. 155-213). Bingley, England: Emerald. https://doi.org/10.1108/S0742-730120170000035005.

Limaj, E., Bernroider, E. W. N., \& Choudrie, J. (2016). The impact of social information system governance, utilization, and capabilities on absorptive capacity and innovation: A case of Austrian SMEs. Information \& Management, 53(3), 380-397. https://doi.org/10. 1016/j.im.2015.12.003.

Litman, D. J., \& Pan, S. (2002). Designing and evaluating an adaptive spoken dialogue system. User model. User-Adapt Interact, 12(2), 111-137. https://doi.org/10.1023/A:1015036910358.

Lyytinen, K., \& Yoo, Y. (2002). Ubiquitous computing. Communications of the ACM, 45(12), 63-96.

Maedche, A., Morana, S., Schacht, S., Werth, D., \& Krumeich, J. (2016). Advanced user assistance systems. Business \& Information Systems Engineering, 58(5), 367-370. https://doi.org/10.1007/s12599-0160444-2.

March, J. G. (1991). Exploration and exploitation in organizational learning. Organization Science, 2(1), 71-87. https://doi.org/10.1287/ orsc.2.1.71.

Markus, M. L., \& Silver, M. S. (2008). A foundation for the study of IT effects: A new look at DeSanctis and Poole's concepts of structural features and spirit. Journal of the Association for Information Systems, 9(10/11), 609-632.

Mauldin, M. L. (1994). Chatterbots, tinymuds, and the turing test: Entering the loebner prize competition. Proceedings of the Twelfth National Conference on Artificial Intelligence, 16-21. Retrieved March 22, 2018, from http://www.aaai.org/Papers/AAAI/1994/ AAAI94-003.pdf .

Maznevski, M. L., \& Chudoba, K. M. (2000). Bridging space over time: Global virtual team dynamics and effectiveness. Organization Science, 11(5), 473-492. https://doi.org/10. 1287/orsc.11.5.473.15200.

McHugh, O., Conboy, K., \& Lang, M. (2011). Using agile practices to influence motivation within it project teams. Scandinavian Journal of Information Systems, 23(2), 85-110.

McKeown, B., \& Thomas, D. (2013). Q methodology. https://doi.org/10. 4135/9781483384412. 
Mettler, T., \& Winter, R. (2016). Are business users social? A design experiment exploring information sharing in enterprise social systems. Journal of Information Technology, 31(2), 101-114.

Mettler, T., \& Wulf, J. (2018). Physiolytics at the workplace: Affordances and constraints of wearables use from an employee's perspective. Information Systems Journal, 29, 245-273. https://doi.org/10.1111/ isj. 12205 .

Mettler, T., Sprenger, M., \& Winter, R. (2017). Service robots in hospitals: New perspectives on niche evolution and technology affordances. European Journal of Information Systems, 26(5), 451-468. https://doi.org/10.1057/s41303-017-0046-1.

Meyer, S. R., Pierce, C. S., Kou, Y., Leonardi, P. M., Nardi, B. A., \& Bailey, D. E. (2015). Offshoring digital work, but not physical output: Differential access to task objects and coordination in globally distributed automotive engineering and graphic design work. In 2015 48th Hawaii international conference on system sciences (pp. 1758-1767). https://doi.org/10.1109/HICSS.2015.213.

Microsoft. (2018). Microsoft AppSource - Business Apps for microsoft teams. Retrieved December 13, 2018, from Microsoft website: https://appsource.microsoft.com/en-us/marketplace/apps?product= office\%3Bteams

Ming, X. G., Yan, J. Q., Wang, X. H., Li, S. N., Lu, W. F., Peng, Q. J., \& Ma, Y. S. (2008). Collaborative process planning and manufacturing in product lifecycle management. Computers in Industry, 59(2), 154-166. https://doi.org/10.1016/j.compind.2007.06.012.

Mirsch, T., Lehrer, C., \& Jung, R. (2017). Digital nudging: Altering user behavior in digital environments. Wirtschaftsinformatik 2017 Proceedings.

Myers, M. D., \& Newman, M. (2007). The qualitative interview in IS research: Examining the craft. Information and Organization, 17(1), 2-26. https://doi.org/10.1016/j.infoandorg.2006.11.001.

Nass, C., \& Moon, Y. (2000). Machines and mindlessness: Social responses to computers. Journal of Social Issues, 56(1), 81-103. https://doi.org/10.1111/0022-4537.00153.

Nass, C., Steuer, J., \& Tauber, E. R. (1994). Computers are social actors. Proceedings of the SIGCHI Conference on Human Factors in Computing Systems, 72-78. https://doi.org/10.1145/191666. 191703

Nass, C., Moon, Y., Fogg, B. J., Reeves, B., \& Dryer, D. C. (1995). Can computer personalities be human personalities? International Journal of Human-Computer Studies, 2(43), 223-239.

Newell, S., David, G., \& Chand, D. (2007). An analysis of trust among globally distributed work teams in an organizational setting. Knowledge and Process Management, 14(3), 158-168. https://doi. org $/ 10.1002 / \mathrm{kpm} .284$.

Nunamaker, J. F., Derrick, D. C., Elkins, A. C., Burgoon, J. K., \& Patton, M. W. (2011). Embodied conversational agent-based kiosk for automated interviewing. Journal of Management Information Systems, 28(1), 17-48. https://doi.org/10.2753/MIS0742-1222280102.

Oinas-Kukkonen, H., \& Harjumaa, M. (2009). Persuasive systems design: Key issues, process model, and system features. Communications of the Association for Information Systems, 24(1), 28.

Orlikowski, W. J., \& Barley, S. R. (2001). Technology and institutions: What can research on information technology and research on organizations learn from each other? MIS Quarterly, 25(2), 145-165. https://doi.org/10.2307/3250927.

Orlikowski, W. J., \& Iacono, C. S. (2001). Research commentary: Desperately seeking the "IT" in IT research-A call to theorizing the IT artifact. Information Systems Research, 12(2), 121-134.

Orlikowski, W. J., \& Scott, S. V. (2008). 10 Sociomateriality: Challenging the separation of technology, work and organization. Academy of Management Annals, 2(1), 433-474. https://doi.org/10.1080/ 19416520802211644.
Paré, G. (2004). Investigating information systems with positivist case research. The Communications of the Association for Information Systems, 13(1), 57.

Pilato, G., Vassallo, G., Augello, A., Vasile, M., \& Gaglio, S. (2005). Expert chat-bots for cultural heritage. Intelligenza Artificiale, 2(2), 25-31.

Pozzi, G., Pigni, F., \& Vitari, C. (2014). Affordance theory in the IS discipline: A review and synthesis of the literature. AMCIS 2014 Proceedings.

Richter, A., \& Riemer, K. (2013). Malleable end-user software. Business and Information Systems Engineering, 5(3), 195-197. https://doi. org/10.1007/s12599-013-0260-x.

Riemer, K., Schellhammer, S., \& Meinert, M. (Eds.). (2018). Collaboration in the digital age: How technology enables individuals, teams and businesses. Retrieved from https://doi.org/10.1007/ 978-3-319-94487-6.

Robert, L. (2018). Personality in the human robot interaction literature: A review and brief critique. AMCIS 2018 Proceedings.

Roch, J., \& Mosconi, E. (2016, January). The use of social media tools in the product life cycle phases: A systematic literature review. 18301839. https://doi.org/10.1109/HICSS.2016.232.

Rohmann, S., Heuschneider, S., \& Schumann, M. (2014). Social software in new product development-state of research and future research directions. Presented at the AMCIS proceedings 2014.

Savoli, A., \& Barki, H. (2013). Functional affordance archetypes: A new perspective for examining the impact of IT use on desirable outcomes. ICIS 2013 Proceedings.

Schatsky, D., \& Gratzke, P. (2016). The conversational enterprise - how chatbots can answer questions for both customers and employees. Deloitte: University Press.

Schlagwein, D., \& Hu, M. (2016). How and why organisations use social media: Five use types and their relation to absorptive capacity. Journal of Information Technology, 32(2), 194-209. https://doi.org/10.1057/jit.2016.7.

Schlagwein, D., Schoder, D., \& Fischbach, K. (2011). Social information systems: Review, framework, and research agenda. ICIS 2011 Proceedings.

Schleicher, D. J., Baumann, H. M., Sullivan, D. W., Levy, P. E., Hargrove, D. C., \& Barros-Rivera, B. A. (2018). Putting the system into performance management systems: A review and agenda for performance management research. Journal of Management, 44(6), 2209-2245. https://doi.org/10.1177/0149206318755303.

Schmidt, R., \& Nurcan, S. (2009). Augmenting BPM with social software. Lecture Notes in Business Information Processing, 201-206. https://doi.org/10.1007/978-3-642-12186-9 19.

Schmitz, K. W., Teng, J., \& Webb, K. J. (2016). Capturing the complexity of malleable IT use: Adaptive structuration theory for individuals. MIS Quarterly, 40(3), 663-686.

Schuetzler, R., Grimes, M., Giboney, J., \& Buckman, J. (2014). Facilitating natural conversational agent interactions: Lessons from a deception experiment. ICIS 2014 Proceedings.

Seddon, P. B., Calvert, C., \& Yang, S. (2010). A multi-project model of key factors affecting organizational benefits from enterprise systems. MIS Quarterly, 34(2), 305-328.

Sedera, D., \& Lokuge, S. (2017). The role of enterprise systems in innovation in the contemporary organization. In R. D. Galliers \& M.-K. Stein (Eds.), The Routledge companion to management information systems (pp. 276-289). Routledge.

Sedera, D., Lokuge, S., Grover, V., Sarker, S., \& Sarker, S. (2016). Innovating with enterprise systems and digital platforms: A contingent resource-based theory view. Information \& Management, 53(3), 366-379. https://doi.org/10.1016/j.im.2016.01.001.

Serban, I. V., Sankar, C., Germain, M., Zhang, S., Lin, Z., Subramanian, S., ... Bengio, Y. (2017). A deep reinforcement learning chatbot. Retrieved March 22, 2018, from http://arxiv.org/abs/1709.02349 
Seymour, M., Riemer, K., \& Kay, J. (2018). Actors, avatars and agents: Potentials and implications of natural face Technology for the Creation of realistic visual presence. Journal of the Association for Information Systems, 19(10): 953-981. https://doi.org/10.17705/ 1jais. 00515

Shankararaman, V., \& Kit Lum, E. (2013). Integration of social media technologies with ERP:A prototype implementation. AMCIS 2013 Proceedings.

Shirky, C. (2003). Social software: A new generation of tools. Esther Dyson's Monthly Report, 21(5). Retrieved July 20, 2016, from http://www.coulthard.com/library/Files/shirky_2003.pdf

Short, J., Williams, E., \& Christie, B. (1976). The social psychology of telecommunications. London: John Wiley \& Sons, Ltd..

Slack. (2016a). App Directory. Retrieved October 11, 2016, from https:// slack.com/apps

Slack. (2016b). The Slack Platform Roadmap. Retrieved December 29, 2016, from https://medium.com/slack-developer-blog/the-slackplatform-roadmap-34067b054177

Slack. (2017a). Slack API. Retrieved June 1, 2017, from https:// api.slack.com/

Slack. (2017b). Slack: Where work happens. Retrieved June 1, 2017, from https://slack.com/is

Slack Platform Blog. (2016, July 19). Investing in the future of work. Retrieved November 30, 2016, from https://medium.com/slackdeveloper-blog/investing-in-the-future-of-work-d4ffb87f985\#. 1 fns4wife

Smith, W. K., Erez, M., Jarvenpaa, S., Lewis, M. W., \& Tracey, P. (2017). Adding complexity to theories of paradox, tensions, and dualities of innovation and change: Introduction to organization studies special issue on paradox, tensions, and dualities of innovation and change. Organization Studies, 38(3-4), 303-317. https://doi.org/10.1177/ 0170840617693560.

Srikanth, K., \& Puranam, P. (2011). Integrating distributed work: Comparing task design, communication, and tacit coordination mechanisms. Strategic Management Journal, 32(8), 849-875. https://doi.org/10.1002/smj. 908 .

Statista. (2018). Most popular messaging apps 2018. Retrieved March 22, 2018, from https:/www.statista.com/statistics/258749/ most-popular-global-mobile-messenger-apps/

Steinhueser, M., Richter, A., \& Smolnik, S. (2015). How to bridge the boundary? Determinants of inter-organizational social software usage. Electronic Markets, 25(4), 267-281.

Stenner, P. H. D., Cooper, D., \& Skevington, S. M. (2003). Putting the Q into quality of life; the identification of subjective constructions of health-related quality of life using Q methodology. Social Science \& Medicine (1982), 57(11), 2161-2172.

Stephenson, W. (1935). Correlating persons instead of tests. Journal of Personality, 4(1), 17-24. https://doi.org/10.1111/j.1467-6494.1935. tb02022.x.

Stephenson, W. (1986). Protoconcursus: The concourse theory of communication. Operant Subjectivity, 9(2), 37-58.

Stoeckli, E., Uebernickel, F., Brenner, W., Weierich, A., \& Hess, S. (2019). Digital feedback for digital work? Affordances and constraints of a feedback app at InsurCorp. Wirtschaftsinformatik 2019 Proceedings. Presented at the Siegen, Germany. Siegen, Germany.

Storey, V. C., Straub, D. W., Stewart, K. A., \& Welke, R. J. (2000). A conceptual investigation of the e-commerce industry. Communications of the ACM, 43(7), 117-123. https://doi.org/10. $1145 / 341852.341871$.

Strauss, A., \& Corbin, J. (1990). Basics of qualitative research. Newbury Park: Sage.

Strode, D. E., Huff, S. L., Hope, B., \& Link, S. (2012). Coordination in co-located agile software development projects. The Journal of Systems and Software, 85(6), 1222-1238. https://doi.org/10.1016/j. jss.2012.02.017.
Strong, D. M., Johnson, S. A., Tulu, B., Trudel, J., Volkoff, O., Pelletier, L. R., ... Garber, L. (2014). A theory of organization-EHR affordance actualization. Journal of the Association for Information Systems, 15(2), 53-85.

Tapscott, D., \& Williams, A. D. (2008). Wikinomics: How mass collaboration changes everything. Penguin.

The Economist. (2016). Bots, the next frontier. Retrieved May 30, 2017, from http://www.economist.com/news/business-and-finance/ 21696477-market-apps-maturing-now-one-text-based-services-orchatbots-looks-poised

Tilson, D., Lyytinen, K., \& Sørensen, C. (2010). Research commentaryDigital infrastructures: The missing IS research agenda. Information Systems Research, 21(4), 748-759. https://doi.org/10.1287/isre. 1100.0318.

Tractinsky, N., \& Jarvenpaa, S. L. (1995). Information systems design decisions in a global versus domestic context. MIS Quarterly, 19(4), 507-534. https://doi.org/10.2307/249631.

Treem, J. W., \& Leonardi, P. M. (2012). Social media use in organizations: Exploring the affordances of visibility, Editability, persistence, and association. Communication Yearbook, 36, 143-189. https:// doi.org/10.2139/ssrn.2129853.

Tripp, J. F., Riemenschneider, C., \& Thatcher, J. B. (2016). Job satisfaction in agile development teams: Agile development as work redesign. Journal of the Association for Information Systems, 17(4), 267-307.

Tsai, P. (2018). Business chat apps in 2018: Top players and adoption plans. Retrieved December 10, 2018, from https://community. spiceworks.com/blog/3157-business-chat-apps-in-2018-topplayers-and-adoption-plans

Tumbas, S., Berente, N., \& vom Brocke, J. (2018). Digital innovation and institutional entrepreneurship: Chief digital officer perspectives of their emerging role. Journal of Information Technology Impact, 33(3), 188-202. https://doi.org/10.1057/s41265-018-0055-0.

Turing, A. M. (1950). Computing machinery and intelligence. Mind, 59(236), 433-460.

Tushman, M. L., \& O Reilly, C. A. I. (1996). Ambidextrous organizations: Managing evolutionary and revolutionary change. California Management Review, 38(4), 8-30.

Van Exel, J., \& De Graaf, G. (2005). Q methodology: A sneak preview. Retrieved November 11, 2018, from https://www.researchgate.net/ publication/228574836_Q_Methodology_A_Sneak_Preview

Vehviläinen, O. (2014, November 11). ChatOps: Everything about deployments right inside your chat. Retrieved November 30, 2016, from http://blog.flowdock.com/2014/11/11/chatops-devops-withhubot/

Vlaar, P. W. L., van Fenema, P. C., \& Tiwari, V. (2008). Cocreating understanding and value in distributed work: How members of onsite and offshore vendor teams give, make, demand, and break sense. MIS Quarterly, 32(2), 227-255.

Volkoff, O., \& Strong, D. (2017). Affordance theory and how to use it in IS research. In R. D. Galliers \& M.-K. Stein (Eds.), The routledge companion to management information systems (pp. 232-245). New York: Routledge.

vom Brocke, J., Maaß, W., Buxmann, P., Maedche, A., Leimeister, J. M., \& Pecht, G. (2018). Future work and Enterprise systems. Business \& Information Systems Engineering, 60(4), 357-366. https://doi.org/ 10.1007/s12599-018-0544-2.

von Krogh, G. (2012). How does social software change knowledge management? Toward a strategic research agenda. The Journal of Strategic Information Systems, 21(2), 154-164. https://doi.org/10. 1016/j.jsis.2012.04.003.

Walker, D., \& Myrick, F. (2006). Grounded theory: An exploration of process and procedure. Qualitative Health Research, 16(4), 547559. https://doi.org/10.1177/1049732305285972. 
Walsham, G. (1995). Interpretive case studies in IS research: Nature and method. European Journal of Information Systems, 4(2), 74-81. https://doi.org/10.1057/ejis.1995.9.

Walsham, G. (2006). Doing interpretive research. European Journal of Information Systems, 15(3), 320-330. https://doi.org/10.1057/ palgrave.ejis.3000589.

Wang, X., Conboy, K., \& Pikkarainen, M. (2012). Assimilation of agile practices in use. Information Systems Journal, 22(6), 435-455. https://doi.org/10.1111/j.1365-2575.2011.00393.x.

Watson, H. J. (2017). Preparing for the cognitive generation of decision support. MIS Quarterly Executive, 16(3), 153-169.

Watts, S., \& Stenner, P. (2005). Doing Q methodology: Theory, method and interpretation. Qualitative Research in Psychology, 2(1), 67-91. https://doi.org/10.1191/1478088705qp022oa.

Watts, S., \& Stenner, P. (2012). Doing $Q$ methodological research: Theory, method \& interpretation. SAGE.

Weinmann, M., Schneider, C., \& vom Brocke, J. (2016). Digital Nudging. Business \& Information Systems Engineering, 58(6), 433-436. https://doi.org/10.1007/s12599-016-0453-1.

Weizenbaum, J. (1966). ELIZA - A computer program for the study of natural language communication between man and machine. Communications of the ACM, 9(1), 36-45.

Wingreen, S. C., LeRouge, C., \& Blanton, J. E. (2009). Structuring training for IT professionals and the firm: An application of the Q- methodology. International Journal of Global Management Studies, 1(1), 53-67.

Yin, R. K. (2008). Case study research: Design and methods. SAGE Publications.

Yoo, Y. (2010). Computing in everyday life: A call for research on experiential computing. MIS Quarterly, 34(2), 213-231.

Yoo, Y. (2012). Digital materiality and the emergence of an evolutionary science of the artificial. In P M Leonardi, B. A. Nardi, \& J. Kallinikos (Eds.), Materiality and organizing: Social interaction in a technological world (pp. 134-154). Oxford, UK: Oxford University Press.

Yoo, Y., Boland, R. J., Lyytinen, K., \& Majchrzak, A. (2012). Organizing for innovation in the digitized world. Organization Science, 23(5), 1398-1408. https://doi.org/10.1287/orsc.1120.0771.

You, S., \& Robert, L. P., Jr. (2018). Emotional attachment, performance, and viability in teams collaborating with embodied physical action (EPA) robots. Journal of the Association for Information Systems, 19(5), 377-407.

Zabala, A., \& Pascual, U. (2016). Bootstrapping Q methodology to improve the understanding of human perspectives. PLoS One, 11(2), e0148087. https://doi.org/10.1371/journal.pone.0148087.

Publisher's note Springer Nature remains neutral with regard to jurisdictional claims in published maps and institutional affiliations. 